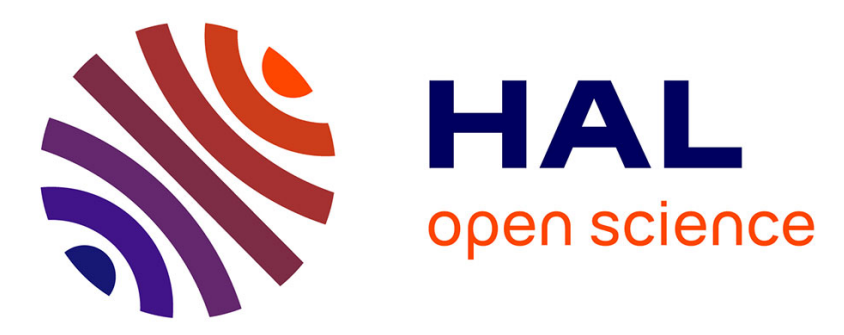

\title{
Dp71 contribution to the molecular scaffold anchoring aquaporine- 4 channels in brain macroglial cells
}

Mehdi Belmaati Cherkaoui, Ophélie Vacca, Charlotte Izabelle, Anne-cécile

Boulay, Claire Boulogne, Cynthia Gillet, Jean-Vianney Barnier, Alvaro

Rendon, Martine Cohen-salmon, Cyrille Vaillend

\section{To cite this version:}

Mehdi Belmaati Cherkaoui, Ophélie Vacca, Charlotte Izabelle, Anne-cécile Boulay, Claire Boulogne, et al.. Dp71 contribution to the molecular scaffold anchoring aquaporine-4 channels in brain macroglial cells. Glia, 2021, 69 (4), pp.954-970. 10.1002/glia.23941 . hal-03035498

\section{HAL Id: hal-03035498 \\ https://cnrs.hal.science/hal-03035498}

Submitted on 28 Oct 2021

HAL is a multi-disciplinary open access archive for the deposit and dissemination of scientific research documents, whether they are published or not. The documents may come from teaching and research institutions in France or abroad, or from public or private research centers.
L'archive ouverte pluridisciplinaire HAL, est destinée au dépôt et à la diffusion de documents scientifiques de niveau recherche, publiés ou non, émanant des établissements d'enseignement et de recherche français ou étrangers, des laboratoires publics ou privés. 


\section{Dp71 contribution to the molecular scaffold anchoring aquaporine- 4 channels in brain macroglial cells}

Running Title: Dp71 and AQP4 in macroglial cells

Mehdi Belmaati Cherkaoui ${ }^{1}$, Ophélie Vacca ${ }^{1}$, Charlotte Izabelle ${ }^{1}$, Anne-Cécile Boulay $^{2}$, Claire Boulogne ${ }^{3}$, Cynthia Gillet ${ }^{3}$, Jean-Vianney Barnier ${ }^{1}$, Alvaro

Rendon $^{4}$, Martine Cohen-Salmon ${ }^{2}$ and Cyrille Vaillend ${ }^{1}$

${ }^{1}$ Université Paris-Saclay, CNRS, Institut des Neurosciences Paris Saclay, 91190, Gif-surYvette, France

${ }^{2}$ Physiology and Physiopathology of the Gliovascular Unit Research Group, Center for Interdisciplinary Research in Biology (CIRB), Collège de France, Unité Mixte de Recherche 7241CNRS, Unité 1050 INSERM, PSL Research University, Paris, France.

${ }^{3}$ Institute for Integrative Biology of the Cell (I2BC), CEA, CNRS, Univ. Paris-Sud, Université Paris-Saclay, 91198 Gif-sur-Yvette cedex, France

${ }^{4}$ Sorbonne Universités, UPMC Université Paris 06, INSERM, CNRS, Institut de la Vision, Paris, France.

Correspondence: Cyrille Vaillend, Université Paris-Saclay, CNRS, Institut des Neurosciences Paris Saclay, 91190, Gif-sur-Yvette, France. Email : cyrille.vaillend@u-psud.fr

\section{ACKNOWLEDGEMENTS}

This work was supported by Centre National de la Recherche Scientifique (CNRS, France) and University Paris-Sud (France), by grants to C.V. from Association Française contre les Myopathies (AFM-Téléthon, France; grant number 17117), Agence Nationale de la Recherche (ANR, France; grant number ANR-14-CE13-0037-01) and Association Monégasque contre les Myopathies (AMM, Monaco), by a postdoctoral fellowship from AFM (\#18944) to O.V. and a PhD fellowship from Ministère de l'Enseignement Supérieur et de la Recherche (France) to M.B. The present work has benefited from Imagerie-Gif core facility supported by Agence Nationale de la Recherche (ANR-11-EQPX-0029/Morphoscope; ANR-10-INBS-04/FranceBioImaging; ANR-11-IDEX-0003-02/Saclay Plant Sciences). We are grateful to the Zootechnic platform of our institute for mouse breeding, care, and genotyping and to S Guyon for assistance with the confocal microscope.

WORD COUNT: Total: 12170; Abstract: 201; Introduction: 754; Materials and Methods: 1518; Results: 2339; Discussion: 2555; References: 3370; Figure Legends: 1433. 


\begin{abstract}
Intellectual disability in Duchenne muscular dystrophy has been associated with the loss of dystrophin-protein 71, Dp71, the main dystrophin-gene product in the adult brain. Dp71 shows major expression in perivascular macroglial endfeet, suggesting that dysfunctional glial mechanisms contribute to cognitive impairments. In the present study we investigated the molecular alterations induced by a selective loss of Dp71 in mice, using semi-quantitative immunogold analyses in electron microscopy and immunofluorescence confocal analyses in brain sections and purified gliovascular units. In macroglial pericapillary endfeet of the cerebellum and hippocampus, we found a drastic reduction (70\%) of the polarized distribution of aquaporin-4 (AQP4) channels, a 50\% reduction of $\beta$-dystroglycan and a complete loss of $\alpha 1$-syntrophin. Interestingly, in the hippocampus and cortex, these effects were not homogeneous: AQP4 and AQP4ex isoforms were mostly lost around capillaries but preserved in large vessels corresponding to pial arteries, penetrating cortical arterioles and arterioles of the hippocampal fissure, indicating the presence of Dp71-independent pools of AQP4 in these vascular structures. In conclusion, the depletion of Dp71 strongly alters the distribution of AQP4 selectively in macroglial perivascular endfeet surrounding capillaries. This effect likely affects water homeostasis and blood-brain barrier functions and may thus contribute to the synaptic and cognitive defects associated with Dp71 deficiency.
\end{abstract}

KEYWORDS: Dystrophin, gliovascular unit, glymphatic system, blood-brain barrier, intellectual disability. 


\section{TABLE OF CONTENTS IMAGE}

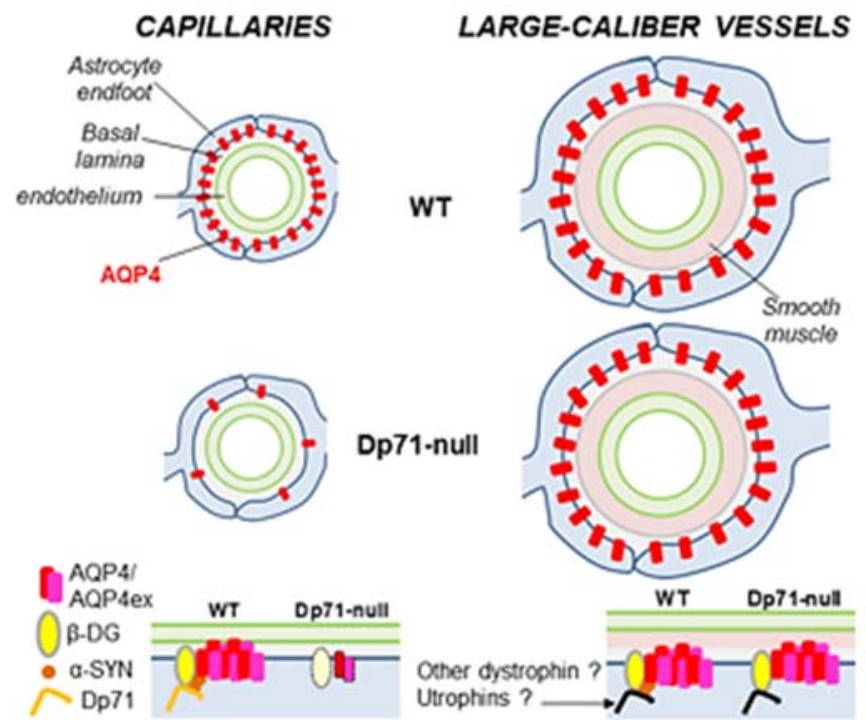

\section{MAIN POINTS}

- Loss of dystrophin-Dp71 impairs expression of AQP4 isoforms in perivascular glial endfeet of capillary, not in larger vessels.

- Expression of other dystrophin proteins or utrophin paralogues may compensate for Dp71 loss in large vessels.

CONFLICT OF INTEREST STATEMENT: The authors declare no potential conflict of interest.

DATA AVAILABILITY STATEMENT: The datasets used and/or analyzed during the current study are available from the corresponding author on reasonable request. 


\section{1 | INTRODUCTION}

Duchenne muscular dystrophy (DMD) is a common and lethal X-linked neuromuscular syndrome caused by mutations in the $d m d$ gene that encodes the dystrophin proteins. DMD is associated with variable degrees of intellectual and behavioral disabilities, depending on the position of the mutations that may lead to the cumulative loss of several brain dystrophins produced from distinct and independent internal promoters in a cell-specific manner (Desguerre et al., 2009). The main brain dystrophins are Dp427, Dp140 and Dp71 in reference to their molecular weights. All dystrophins differ by their N-terminal part but contain a common C-terminal domain, which interacts with the dystrophin-associated protein complex (DAPC), bridging them to the extracellular matrix and to the intracellular actin cytoskeleton as well as cytosolic signaling proteins. The loss of Dp71 is a pivotal aggravating factor for cognitive status in DMD (Daoud et al., 2009a), which frequently associates intellectual disability and neuropsychiatric disturbances such as autism-spectrum disorders (Ricotti et al., 2016). Recent studies in mice with a selective loss of Dp71 (Dp71-null mice) unveiled presence of specific cognitive and executive deficits associated with unbalanced neuronal network excitability and impaired plasticity in various brain structures involved in cognitive processes (Chaussenot, Amar, Fossier, \& Vaillend, 2019; Daoud et al., 2009b; Helleringer et al., 2018). However, the molecular and cellular mechanisms underlying Dp71dependent brain dysfunctions are poorly understood.

Dp71 is the most abundant DMD-gene product in the adult brain. This protein is present in primary astrocytes and neurons and, in vivo, in the perivascular endfeet of brain astrocytes and other types of macroglial cells, including retinal Müller cells and cerebellar Bergmann cells (Naidoo \& Anthony, 2001; Tadayoni, Rendon, Soria-Jasso, \& Cisneros, 2012). In neurons, Dp71 has been described in the nucleus and at the synaptic level (Daoud et al., 2009b). Dp71 is involved in multiple processes including cell cycle, cell differentiation, nuclear and membrane architecture, synaptic structure and function, as well as ion homeostasis (Perronnet \& Vaillend, 2010; Tadayoni, Rendon, Soria-Jasso, \& Cisneros, 2012; for reviews). Several alternatively spliced Dp71 isoforms have been identified in the central nervous system (CNS) (Aragon et al., 2018; Austin, Morris, Howard, Klamut, \& Ray, 2000). These isoforms might play distinct roles, yet their precise cellular distribution and functions remain unclear. We recently showed that the Dp71d subgroup (in which exon 78 is not spliced out), constitutes the majority of Dp71 isoforms (around $80 \%$ ) in the adult brain (Aragon et al., 2018). Importantly, most antibodies against dystrophins are directed against 
their C-terminal part and only recognize the Dp71d isoforms, which appear to have a selective expression in perivascular endfeet of astrocytes and Bergmann macroglial cells in the adult brain (Enger et al., 2012; Haenggi, Schaub, \& Fritschy, 2005; Nicchia, Rossi, Nudel, Svelto, \& Frigeri, 2008a).

In macroglial cells, Dp71d interacts with specific components of the DAPC, notably with $\beta$-dystroglycan, a key transmembrane component of the dystroglycan subcomplex that links the DAPC to extracellular laminins and with $\alpha$-dystrobrevin and $\alpha$-syntrophin which regulate the clustering and distribution of potassium (Kir4.1) and water aquaporin-4 (AQP4) channels at the perivascular endfeet membrane (Tadayoni, Rendon, Soria-Jasso, \& Cisneros, 2012). In consequence, the loss of Dp71 is expected to alter ion and water homeostasis (AmiryMoghaddam, Frydenlund, \& Ottersen, 2004; Kofuji \& Newman, 2004). Supporting this hypothesis, Dp71-null mice show a delocalization of AQP4 and Kir4.1 channels in the perivascular endfeet of retinal Müller cells, associated with altered potassium buffering, defective osmoregulation, increased blood-retinal barrier permeability, sensitivity to edema and altered retinal physiology (Barboni et al., 2020; Dalloz et al., 2003; El Mathari et al., 2015; Sene et al., 2009; Vacca et al., 2016). Importantly, AQP4 is exclusively expressed in macroglia and was recently associated with language-associated learning in humans (Woo et al., 2018), while its loss in mice induces phenotypes reminiscent to those previously reported in Dp71-null mice (Chaussenot, Amar, Fossier, \& Vaillend, 2019; Daoud et al., 2009b), such as impaired hippocampal synaptic plasticity and spatial learning deficits (Hubbard, Szu, \& Binder, 2018). Therefore, altered AQP4 distribution in astrocytes may contribute to the cognitive deficits associated with Dp71 loss of function in DMD.

In the present study, we examined the distribution of AQP4 and dystrophin-associated proteins in Dp71-null mice by semi-quantitative immunogold electron and/or immunofluorescence confocal microscopy in distinct layers of the cerebellum and in the hippocampus, two brain areas associated with cognitive deficits in this mouse model. Our study demonstrates that while AQP4 and Dp71 are homogeneously distributed in macroglial perivascular endfeet, AQP4 anchorage mechanisms are heterogeneous among cerebellar and hippocampal areas and vascular elements. These results highlight the diversity of the gliovascular unit molecular architecture and extend our understanding of the molecular alterations induced by Dp71 deficiency in the brain. 


\section{2 | MATERIALS AND METHODS}

\subsection{Animals}

Dp71-null breeders were kindly provided by Prof. David Yaffe (Weizmann Institute of Science, Rehovot, Israel), who originally produced this mouse line by homologous recombination, by replacing most of the first Dp71-specific exon and a small part of the first intron with the promoterless gene encoding a $\beta$-Gal-neomycin resistance chimeric protein. This specifically abolished expression of Dp71 without interfering with other dmd-gene products (Sarig et al., 1999). Dp71-null mice were backcrossed for more than 10 generations with C57BL/6JRj mice (Janvier Labs, France) by Dr. Alvaro Rendon (Institut de la Vision, Paris, France) at CDTA (CNRS, Orléans, France). Production and maintenance was undertaken in our mouse facility by crossing heterozygous females with C57BL/6JRj males to generate Dp71-null and wild-type littermate control males (WT). Genotypes were determined by PCR analysis of tail DNA. Animals were kept under a $12 \mathrm{~h}$ light-dark cycle (light on 7.00 am) with food and water ad libitum. Brain tissues were collected in adult mice (2.5-5 months old) following guidelines of our mouse facility (agreement \#D91-471-104) in compliance with European Directive 2010/63/EU, French National Committee (87/848) and local Ethics Committee (Paris Centre et Sud, \#59).

\subsection{Antibodies and cell immunomarkers}

The rabbit polyclonal IgG antibodies were: H4 directed against exons 78-79 of the C-terminus dystrophin (1:400), LG5 anti- $\beta$-dystroglycan (1:400) and K7 anti-utrophin (1:200) (gift from D. Mornet, Montpellier), anti-Aquaporin-4 (AQP4 300-314; 1:400; Alomone labs, Israël), anti-AQP4ex (60789S, 1:400, Ozyme, France), anti-alpha-1 syntrophin (1:200; Alomone labs, Israël), anti-alpha smooth muscle actin (anti-SMA; 1:200; Sigma) and anti-Glial Fibrillary Acidic Protein (anti-GFAP; 1:1000, Dako, Denmark). The mouse monoclonal antibodies were: Anti-GFAP (1:500, Sigma-Aldrich), sc-390488 anti-AQP4 (1:50 in westernblots; Santa Cruz Biotechnology) and anti-Dp427 N-terminal NCL-Dys1 (diluted 1:3; Leica Biosystem). The secondary antibodies were: goat anti-rabbit conjugated to Cy3 (diluted 1:400, Jackson Immunoresearch, USA) and goat anti-mouse IgG H\&L (diluted 1:400, Alexa Fluor ${ }^{\circledR ~ 647, ~}$ Abcam). The Lycopersicon esculentum lectin Dy-Light 488 (1:100, Vector laboratories), specific of N-acetyl-D-glucosamin and $\mathrm{N}$-acetyl-polylactosamine oligomers (Kawashima, Sueyoshi, Li, Yamamoto, \& Osawa, 1990; Porter, Palade, \& Milici, 1990), was used as an 
endothelial marker to label the vessels and as a control for normalization of immunofluorescence quantifications.

\subsection{Western blots}

For analyses of dystrophin expression in hippocampal samples, the hippocampus was dissected out following cervical dislocation and then frozen in liquid nitrogen with ceramic beads (MO Bio kit, Qiagen). Samples were homogenized by centrifugation (6800g, 20s, 2-3 times) in a RIPA-Sodium dodecyl sulfate (SDS) lysis buffer with Halt protease inhibitor cocktail (1X). Protein content was quantified using the Pierce ${ }^{\mathrm{TM}}$ BCA protein assay kit (Life Technologies, France). Proteins $(50 \mu \mathrm{g})$ were separated on NuPAGE ${ }^{\circledR}$ Tris-Acetate $4-12 \%$ gradient gels (Invitrogen) at $150 \mathrm{~V}$ for $1 \mathrm{~h} 15$ and electrotransferred $(30 \mathrm{~V}, 1 \mathrm{~h})$ onto polyvinylidene difluoride membranes (PVDF; Millipore, USA). PVDF membranes were blocked for $1 \mathrm{~h}$ at room temperature (RT) in Pierce ${ }^{\mathrm{TM}}$ Milk Blocking buffer (Life Technologies, France) and then incubated overnight at $4^{\circ} \mathrm{C}$ in the same blocking buffer with the primary pan-specific polyclonal antibodies directed against dystrophins (H4, 1:5000). Membranes were then washed and incubated for $1 \mathrm{~h}$ at RT with a goat anti-rabbit secondary antibody conjugated to horseradish peroxidase (Jackson Immunoresearch laboratories). A monoclonal anti- $\beta$-actin antibody (1/15000, Sigma-Aldrich) was used as loading controls to normalize expression levels in each sample. Enhanced chemiluminescence (ECL) was performed using ECL plus Western blotting detection system (GE Healthcare, Germany) and gels were analyzed using a C-Digit Li-Cor scanner and Image Studio software.

For analyses in purified gliovascular units, the pellets were homogenized in $50 \mu \mathrm{L}$ of SDS2\%

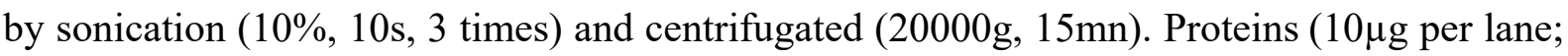
each lane was a pool of 3 mouse brains in order to obtain sufficient quantities of proteins) were separated using Criterion ${ }^{\mathrm{TM}}$ TGX (Tris-glycine) Stain-Free ${ }^{\mathrm{TM}} 4-15 \%$ gels (BioRad) and electrotransferred to nitrocellulose membranes using the Trans-blot Turbo Transfer System (Biorad). Polyclonal antibodies were used to detect AQP4 (Santa Cruz, 1:50) or AQP4x (Cell Signaling, 1:500). Normalization was obtained using stain-free signal on membranes obtained using the Gel DocTM EZ Imager (Biorad). 


\section{4 | Immunofluorescence studies}

\section{Preparation of tissue sections}

Brains were dissected out following cervical dislocation, fresh frozen in powdered dry ice. Sagittal cerebellar sections (formalin fixed: $12 \mu \mathrm{m}$ thick; fresh-frozen: $30 \mu \mathrm{m}$ thick) were cut in a cryostat and collected on SuperFrost Plus glass slides (Roth, France) and stored at $-80^{\circ} \mathrm{C}$. Tissue sections were postfixed in acetone-methanol $\left(1: 1,-20^{\circ} \mathrm{C}, 5 \mathrm{~min}\right)$ before immunochemistry, as previously described (Daoud et al., 2009b; Vaillend et al., 2010).

\section{Purification of gliovascular units}

Mechanical purification of brain vessels with perivascular-associated astrocyte endfeet from 7-month-old mice was performed as previously described (Boulay, Saubaméa, Declèves, \& Cohen-Salmon, 2015). Vessels were filtered onto a $100 \mu \mathrm{m}$-mesh filter to preferentially retain larger vessels while the flow-through containing microvessels was filtered on a $20 \mu \mathrm{m}$-mesh filter. Vessels were immobilized on a glass slide coated with Cell Tak (Corning) and fixed with $4 \%$ Paraformaldehyde for 15 min before immunocytochemistry.

\section{Immunochemistry}

Tissue sections and purified gliovascular units were washed 3 times in $0.1 \mathrm{M}$ phosphatebuffered saline (PBS), incubated for $45 \mathrm{~min}$ in a blocking solution containing 10\% normal goat serum, $0.3 \%$ Triton $\mathrm{X}-100$, and $1 \%$ bovine serum albumin (BSA), then overnight at $4{ }^{\circ} \mathrm{C}$ with the primary antibodies and Lycopersicon esculentum lectin Dy-Light 488 (Vector laboratories). They were then washed, incubated $1 \mathrm{~h}$ at RT with secondary antibodies (1:500) conjugated to Alexa fluor (Invitrogen, France) or Cyanine 3 (Jackson ImmunoResearch, USA) and coverslipped using a medium containing an instant-blue nuclear probe fluorescing (405 nm) compound (DAPI Fluoromount-G, Clinisciences, France). No staining was observed when primary antibody was omitted.

\section{Confocal image analyses}

Images were collected using a laser scanning confocal microscope LSM 700 (Zeiss) at 555 $\mathrm{nm}, 488 \mathrm{~nm}, 647 \mathrm{~nm}$ (or $694 \mathrm{~nm}$ for anti-rat secondary antibody) and $405 \mathrm{~nm}$ for DAPI. Sequential dual-channel recording of multi-labeled sections were taken at equivalent locations and exposure times in both genotypes and the intensity of the excitation lines for secondary antibodies and DAPI was adjusted to avoid cross-excitation of the fluorochromes. For quantification, stacks of images $(106.7 \mu \mathrm{m} \times 106.7 \mu \mathrm{m})$ spaced by $300 \mathrm{~nm}$ were imported using EC Plan-Neofluar x40 objectives and were taken with constant settings (1024 x 1024 
px; $313 \mathrm{~nm} / \mathrm{px}$ resolution). Images were processed with ImageJ using a maximum intensity projection of all the z-stack images and were then $\mathrm{Z}$ projected. The fluorescence area was quantified with the Image J software and a total tissue surface of $39375 \mu \mathrm{m}^{2}$ per mouse was sampled. Relative expression of the target proteins expressed along the walls of blood vessels was normalized to that of the endothelial surface marker lectin, i.e. as a parameter reflecting the vascular density in each image.

\section{5 | Immunogold electron microscopy}

Mice were deeply anesthetized by intraperitoneal injection of a ketamine $(60 \mathrm{mg} / \mathrm{kg}) /$ Médétomidine (Domitor $\left.{ }^{\circledR}\right)(1 \mathrm{mg} / \mathrm{kg}) \mathrm{mix}$ and received intracardiac injection of $0.1 \mathrm{ml}$ heparin (500 UI). They were then intracardially perfused $(7.5 \mathrm{ml} / \mathrm{min})$ with a $0.1 \mathrm{M}$ phosphate buffer (PB) containing heparin (10 UI) for 30s and then with $60 \mathrm{ml}$ of a fixative solution containing 4\% PFA and 1.2\% picric acid in $0.1 \mathrm{M} \mathrm{PB}(\mathrm{pH} 7.3-7.4)$. Brains were removed from skull and postfixed overnight in 4\% PFA. The cerebellum was then cut as $300 \mu \mathrm{m}$-thick sagittal slabs with a vibrating microtome (VT 1000 S, Leica, Vienna, Austria). Pieces of cerebellar lobules were dissected under stereomicroscope (1-2 mm, 5th-6th lobules around primary fissure, lateral 1.68-0.84) (Paxinos \& Franklin, 2001) and cryoprotected by immersion in graded concentrations of glycerol (10, 20, 30 \%). Punches of tissue section (1 $\mathrm{mm}$ in diameter) including glia limitans, molecular cell and Purkinje cell layers were cryofixed by High Pressure Freezing (EMPACT2, Leica). The samples were then processed and sectioned as previously described (Puwarawuttipanit et al., 2006), briefly: a freezesubstitution in $1 \%$ uranyl acetate in methanol at $-90^{\circ} \mathrm{C}$ for $12 \mathrm{~h}$ (AFS2, Leica) and embedding in Lowicryl ${ }^{\circledR} \mathrm{HM} 20$ resin (EMS, \#14345) at $-45^{\circ} \mathrm{C}$ for 2 days. For immunolabeling, 70nmsections cut with a $35^{\circ}$ diamond knife were floated successively 5 min in $0.5 \%$ Tween-PBS, $10 \mathrm{~min}$ in 50mM Glycine-PBS, 30min in Blocking solution (Aurion, \#905.002), 10min in $0.1 \%$ BSAc-PBS (Aurion, \#900.099) and incubated overnight at $4^{\circ} \mathrm{C}$ in the rabbit polyclonal anti-AQP4 primary antibody (1:40; Alomone, Israel). The sections were then washed several times in PBS-BSAc and incubated $30 \mathrm{~min}$ at RT with a 1:20 dilution of a goat F(ab')2 antirabbit secondary antibody conjugated to $10-\mathrm{nm}$ gold particles (Aurion). They were rinsed several times in PBS and ultrapure water and contrasted with uranyl acetate (10 min) and lead citrate $(5 \mathrm{~min})$. Control sections were obtained by omitting the primary antibody.

Transmission Electron microscopic micrographs were obtained at 7000x using a JEOL1400 microscope operating at $80 \mathrm{kV}$ and equipped with a digital camera (Gatan Orius). 
Experiments were conducted in 2 mice of each genotype ( 3 grids and at least 25 images per mouse). Quantification was obtained by manually counting the gold beads located at the glial endfeet membranes along cross-sectional capillaries $(n=18$ capillaries and $>290 \mu m$ membrane length per genotype) and glia limitans ( $>250 \mu \mathrm{m}$ membrane length per genotype). Membrane lengths were measured using the Fiji software (https://fiji.sc/) by boundary tracing of membranes from mosaic images in order to express counts as the number of gold beads per $\mu \mathrm{m}$.

\section{6 | Statistics}

Data are expressed as means \pm standard error of the meam (SEM). Genotype effects were evaluated by Mann-Whitney nonparametric tests considering P-values $<0.05$ as statistically significant.

\section{3 | RESULTS}

\subsection{Localization of Dp71 in hippocampus and cerebellum and characterization of Dp71-null mice}

Detection of Dp71 in brain tissue sections was obtained using the H4 polyclonal antibody directed against the C-terminal part of dystrophins. A strong and homogeneous immunoreactivity (IR) was detected along the walls of capillaries and larger blood vessels in hippocampus and cerebellar lobules in WT mice, as well as in the glial endfeet under the pia mater (glia limitans, GL) in the cerebellum (Fig. 1 A). This labelling was absent in tissue sections from Dp71-null mice, indicating the specificity of the antibody. High-resolution confocal images taken at higher magnification in tissue sections double-stained with the H4 antibody and Lycopersicon esculentum lectin, an endothelium surface marker, confirmed that Dp71-IR surrounds blood vessels. No overlap between the two IR signals was detected in WT mice (Fig. 1 B). Hence, Dp71 expression is distributed along the perivascular membrane of astrocyte perivascular endfeet in both cerebellum and hippocampus.

\subsection{Dp71-independent and dependent pools of AQP4 in the cerebellum}

The expression of AQP4 in cerebellar sections from WT and Dp71-null mice was characterized using immunofluorescence and confocal microscopy. As shown in Fig. 2 A, in WT mice AQP4-IR was detected along the walls of capillaries of the molecular cell layer 
(MCL) and along the glia limitans (GL), while a more diffuse staining was also observed in the granular cell layer (GCL) and in the white matter (WM). The staining observed at the limit between the Purkinje cell layer (PCL) and the GCL, i.e., below the cell soma of Purkinje neurons and Bergmann glial cells, is believed to reflect the polarized expression of AQP4 in endfeet of velate astrocytes of the GCL and/or proximal processes of Bergmann glial cells, as suggested by others (Blauth et al., 2015; Farmer et al., 2020; Nicchia, Rossi, Nudel, Svelto, \& Frigeri, 2008a; Stavale, Soares, Mendonça, Irazusta, \& Da Cruz Höfling, 2013; Wen et al., 1999). The Bergmann glial cell is one particular and major glial cell subtype present in the MCL. Its soma is located among neurons within the Purkinje cell layer (PCL) and its radial processes pass through the MCL up to the glia limitans (GL). In Bergmann glial cells, AQP4 is anchored at the perivascular membrane of endfeet surrounding capillaries of the MCL and forming the GL (Nicchia, Rossi, Nudel, Svelto, \& Frigeri, 2008a). This was clearly illustrated by the staining obtained with the anti-AQP4 antibody at the level of capillaries in the MCL and along the GL in WT mice. Thus, AQP4 expression paralleled the pattern of expression of Dp71 in glial endfeet of Bergmann cells (Fig. 1 A). In Dp71-null mice, the loss of Dp71 was associated with a strong reduction of the AQP4 immunolabeling along the MCL vessel walls, with however a residual perivascular expression of about $30 \%$ of WT levels (Fig. 2 B). It likely corresponded to a glial expression since it did not overlap with lectin in high magnification images of capillary's transversal planes (Supplementary Fig. S1). Likewise, there was also a residual expression of AQP4 along the glia limitans in Dp71-null mice (Fig. 2 A).

The diffuse AQP4-IR observed in the GCL and WM in both WT and Dp71-null mice did not follow the Dp71 pattern of expression (Fig. 1 A), suggesting the presence of a distinct Dp71independent pool of AQP4 channels in these cerebellar layers. Preserved expression of AQP4 in the GCL of mice lacking Dp71 has been previously reported by others (Nicchia, Rossi, Nudel, Svelto, \& Frigeri, 2008a). Here we further detailed this observation by showing that AQP4-IR overlapped with GFAP-IR in astrocytes of the GCL, while it followed the fiber tracks in the WM (Supplementary Fig. S2 A-B). The quantification of AQP4-IR demonstrated that AQP4 expression is fully preserved in the GCL and WM in Dp71-null mice (Supplementary Fig. S2 B). This suggests that Dp71 is only involved in the polarized distribution of AQP4 channels at the perivascular endfeet membrane of Bergmann glial cells, whereas AQP4 expression in other cell types does not depend on Dp71. 
To confirm the reduction of AQP4 expression and assess its distribution at the ultrastructural level in Bergmann glial cell endfeet, we performed immunogold labeling and transmission electron microscopy (Fig. 2 C-D). AQP4 channel expression was analyzed in the endfeet surrounding capillaries (Fig. 2 C) and forming the GL (Fig. 2 D). Non-specific binding was minimal when the primary antibody was omitted $(<0.1$ beads $/ \mu \mathrm{m})$. The mean density of AQP4 channels was decreased by more than $50 \%$ in glial endfeet of Dp71-null mice for both capillaries $(\sim 60 \%)$ and glia limitans $(\sim 80 \%)$. Hence a level of residual expression of AQP4 of about $20-40 \%$ of WT levels, in agreement with our semi-quantitative immunofluorescence analysis.

Distribution of AQP4 in astrocyte perivascular membranes depends on several dystrophinassociated proteins (DAPs), such as the transmembrane $\beta$-dystroglycan and cytosolic $\alpha$ syntrophin (Amiry-Moghaddam et al., 2003a; Frigeri et al., 2001; Inoue et al., 2002; Neely et al., 2001). We therefore characterized their cerebellar expression in WT and Dp71-null mice (Fig. 2 E-F). Both DAPs showed a Dp71-like expression pattern in the perivascular regions and along the GL in WT mice. In Dp71-null mice, the expression of $\beta$-dystroglycan was reduced by about 50-60\% (Fig. 2 E). Part of $\beta$-dystroglycan residual staining was detected in lectin-negative elements (Supplementary Fig. S1), suggesting expression in glial endfeet. In contrast with $\beta$-dystroglycan, $\alpha$-syntrophin IR was virtually undetectable in Dp71-null mice (Fig. 2 F).

This analysis in cerebellum indicates a critical but selective role of Dp71 in the distribution of AQP4 channels in Bergmann glial perivascular endfeet. Moreover, Dp71 loss differently alters the expression of distinct DAPs in perivascular domains.

\section{3 | Dp71-independent and dependent pools of AQP4 in the hippocampus}

The distribution of AQP4 and DAPs was then analyzed in the forebrain, firstly in the hippocampus (Fig. 3), another brain structure in which Dp71-dependent alterations likely contribute to the genesis of cognitive deficits in Dp71-null mice (Chaussenot, Amar, Fossier, \& Vaillend, 2019; Daoud et al., 2009b). Alike in cerebellum, AQP4 (Fig. 3 A) and $\beta$ dystroglycan (Fig. 3 B) pericapillary IR was strongly reduced in Dp71-null mice in all hippocampal layers. However, the expression of both proteins was preserved around arterioles of the stratum lacunosum moleculare (SLM) in Dp71-null mice, indicating that the lack of Dp71 rather affects capillaries than larger vessels. In details, AQP4 and $\beta$-dystroglycan staining in Dp71-null mice was estimated less than 50\% of WT in dendritic layers of stratum 
oriens (SO) and stratum radiatum (SR) containing capillaries, but was comparable to WT in the SLM which contains large-diameter arterioles and precapillary arterioles. In contrast, $\alpha-$ syntrophin was undetectable in all hippocampal layers (Fig. 3 C; Supplementary Fig. S1). Thus, the loss of Dp71 affects the level of astrocyte perivascular AQP4 and $\beta$-dystroglycan in specific hippocampal subfields, depending on their presence around capillaries or arterioles, while the effect is more general for $\alpha$-syntrophin.

\subsection{Dp71-independent and dependent pools of AQP4 in the cortex}

The expression pattern of AQP4 and DAPs in cortical layers (Fig. 4) was comparable with that revealed in the hippocampus: The lack of Dp71 was mainly characterized by a strong reduction of AQP4 and DAPs pericapillary expression. In Dp71-null mice, dystrophin pericapillary IR was lost but a faint staining remained in vascular structures of superficial cortical (pial) vessels and penetrating arterioles (Fig. 4 A), suggesting putative expression of another dystrophin in large cortical vessels. Likewise, there was a persistent expression of $\beta$ dystroglycan (Fig 4 B) in these vascular structures, while $\alpha$-syntrophin was undetectable (Fig. 4 C). As shown in Fig. 4 D, AQP4 IR was also clearly preserved in Dp71-null mice around the pial artery and penetrating cortical arterioles, including within the interhemispheric fissure. This confirms that Dp71 loss has a drastic impact on AQP4 polarization in pericapillary domains while AQP4 distribution in large vessels (arteries, arterioles) is largely unaffected.

\subsection{AQP4 isoforms in forebrain vasculature}

The detection and quantification of the main AQP4 isoforms, M1 and M23, as well as AQP4ex, was first analyzed by western blot of purified forebrain gliovascular units (Fig. 5 A). Expression levels of both M1 and M23 isoforms were drastically reduced in Dp71-null mice, indicating that the loss of Dp71 alters the co-expression of these isoforms in gliovascular units. Interestingly, the M1/M23 ratio was decreased in Dp71-null mice, suggesting a more important impact of Dp71 loss on expression of the M1 isoform. The expression level of AQP4ex in gliovascular units was also drastically reduced in Dp71-null mice (Fig. 5 A).

The purification of gliovascular units allowed us to collect samples containing vessels of 20$100 \mu \mathrm{m}$ diameters, but this could not be used to compare expression levels of AQP4 isoforms in capillaries and larger vessels in western blots. While there is currently no selective 
antibody to discriminate M1 and M23 isoforms on tissue sections, for AQP4ex our selective antibody allowed us to perform IF analyses of its distribution in cerebellum, hippocampus and cortex (Fig. 5 B). The pattern of AQP4ex IR was comparable with that of AQP4 in all structures, i.e., showing expression around both capillaries and large vessels in WT mice, and preserved expression only around large vessels in the Dp71-null mouse. This strengthened our conclusions and confirmed that AQP4ex is crucial for anchoring of perivascular AQP4 as suggested by others (Palazzo et al.; 2019).

\subsection{Subcellular expression of AQP4 and associated proteins in forebrain vasculature}

To further explore the effect of Dp71 loss at the gliovascular interface, we performed immunofluorescent detection of AQP4, $\beta$-dystroglycan and Dp71 in purified gliovascular units from forebrain capillaries of WT and Dp71-null mice (Fig. 6 A-C). Compared to the continuous IR seen in WT mice, gliovascular units from Dp71-null mice displayed a reduced and discontinuous staining for AQP4 (Fig. 6 A) and $\beta$-dystroglycan (Fig. 6 B), which reinforced our observations in tissue sections. Thus, Dp71 inactivation in capillaries leads to partial depletion and/or impaired spatial distribution of astrocyte perivascular AQP4 and $\beta$ dystroglycan, which further highlights the major role of Dp71 in the polarized clustering of these proteins at the glial endfeet membrane. Importantly, using our H4 pan-specific antibody that recognizes all dystrophins (Fig. 6 C) we did not detect any dystrophin-IR in the capillaries, indicating that residual expression of AQP4 and $\beta$-dystroglycan did not involve other dystrophin-gene products.

We next focused on the subcellular expression of AQP4 in arterioles of the hippocampal SLM region (Fig. 6 D-G). We first performed double immunofluorescence staining in hippocampal tissue sections using the anti-AQP4 antibody and the anti-GFAP glial marker, along with affinity staining with the endothelial marker, lectin (Fig. 6 D). In both WT and Dp71-null mice, AQP4-IR overlapped GFAP-IR, indicating strong expression of AQP4 at the membrane of glial endfeet contacting arterioles in both WT and Dp71-null mice. $\beta$-dystroglycan was also detected in lectin-negative domains surrounding large-diameter vessels of the SLM in both genotypes (Fig. 6 E), suggesting it may also participate in the clustering of AQP4 channels in the glial domains surrounding these vessels.

We hypothesized that the absence of effect of Dp71 depletion in large-diameter vessels could be due to the expression of dystrophin paralogues such as utrophins (Perronnet et al., 2012) or of other brain dystrophins. The K7 pan-specific antibody that recognizes all utrophin-gene 
products gave a strong immunoreactive signal in both capillaries and arterioles (Fig. 6 F). Utrophins IR fully overlapped lectin staining in capillaries, indicating endothelial expression as previously demonstrated by others (Haenggi, Soontornmalai, Schaub, \& Fritschy, 2004). In larger vessels of the SLM, however, only a part of the utrophin IR overlapped with lectin, suggesting that some utrophin-gene products could also be expressed in glial compartments around arterioles. Then, using the H4 antibody directed against all dystrophins, we detected dystrophin-IR in both GFAP-positive and lectin-positive domains (Fig. 6 G). In WT mice, most of dystrophin-IR was in GFAP-positive structures surrounding the arterioles. In Dp71null mice, a punctate dystrophin-IR was detected in GFAP-positive domains and a diffuse dystrophin-IR in lectin-positive domains. This suggests that other brain dystrophins are expressed around large vessels of hippocampal SLM, both in glial endfeet and vascular cells (endothelial and/or smooth muscle cells). In contrast to capillaries, the presence of another dystrophin could explain that the clustering of AQP4 is preserved around the large vessels in Dp71-null mice.

We further explored the possibility that other dystrophins could be expressed in hippocampal arterioles. Using the same pan-specific anti-dystrophin antibody in Western blot experiments, we first showed that several brain dystrophins are expressed in the hippocampus (Fig. 7 A, left panel). We performed a semi-quantitative evaluation of Dp427, Dp140 and Dp71 levels in WT and Dp71-null mice. As expected Dp71 was absent in extracts from Dp71-null mice. However, we detected Dp427 in both genotypes and it was slightly more present in Dp71-null mice (Fig. 7 A, right panel). We next used the monoclonal DYS1 antibody directed against the N-terminal part of the full-length dystrophin (Dp427), to perform immunofluorescence in hippocampal tissue sections and determine its putative expression in glial or vascular elements. As expected, we detected Dp427 neuronal expression characterized by punctate staining in synapses of pyramidal neurons, while it was absent in the capillaries (not shown). At the level of the large vessels of the SLM, there was a DYS1-positive staining revealing expression of Dp427 in or around vascular cells. In details, this DYS1-positive staining was apparently located between GFAP-positive and lectin-positive domains, suggesting expression in smooth muscle rather than glial or endothelial structures (Fig. 7 B). To test this hypothesis, we used triple staining of Dp427 (DYS1 antibody), alpha-smooth muscle actin (anti- $\alpha$-SMA antibody) and lectin Dy-Light 488. As shown in Fig. 7 C, the anti- $\alpha$-SMA antibody only labeled the larger segments of precapillary arterioles in hippocampal tissue sections, not the smaller lectin-positive precapillary arterioles and capillaries. Likewise, 
Dp427-IR was only found surrounding large-diameter arterioles but not in smaller lectinpositive vascular elements. This was confirmed by showing a full overlap of DYS1-IR and $\alpha-$ SMA-IR in purified arterioles in both WT and Dp71-null mice, while the DYS1-IR showed no overlap with endothelial lectin (Fig. 7 D).

Hence, the vascular expression of Dp427 was restricted to arterioles containing smooth muscle. The dystrophin detected in GFAP-positive cellular elements around arterioles (Fig. 6 G) may therefore correspond to the expression of another brain dystrophin-gene product.

\section{4 | DISCUSSION}

The most severe cases of intellectual disability (ID) in DMD occur when all dystrophins including Dp71 are missing (Daoud et al., 2009a), yet it was also reported that a selective loss of Dp71 function can induce ID without muscular dystrophy (De Brouwer et al., 2014). The major expression of Dp71 at the gliovascular interface in the adult brain suggests that a dysfunctional glial mechanism contributes to ID in this syndrome (Ricotti, Roberts, \& Muntoni, 2011). Converging evidence indicate that the loss of Dp71 impairs the clustering of aquaporin (AQP4) water channels in the glial endfeet adjacent to capillaries, which may induce critical alterations in water and ion brain homeostasis, vascular permeability, synaptic plasticity and cognitive functions (Amiry-Moghaddam, Hoddevik, \& Ottersen, 2010; Hubbard, Szu, \& Binder, 2018). In the present study, we studied the Dp71-null mouse in order to characterize the altered distribution of AQP4 channels in main brain structures that have been associated with cognitive and neurophysiological defects in this mouse, the cerebellum (Helleringer et al., 2018), hippocampus and cortex (Chaussenot, Amar, Fossier\& Vaillend, 2019; Daoud et al., 2009b). We found a residual expression of AQP4 in selective layers of these brain structures and in specific gliovascular elements, thus highlighting that the loss of Dp71 cannot fully recapitulate the glial and vascular alterations reported in AQP4-KO mice.

The link between Dp71 and AQP4 channels in brain glial cells was originally investigated using pan-specific anti-dystrophin antibodies in mouse models lacking several dystrophingene products, such as the $\mathrm{mdx} 3 \mathrm{cv}$ mouse, leaving some uncertainty regarding the specific impact of Dp71 loss on expression and distribution of Dp71-associated proteins (e.g., Enger et al., 2012; Haenggi, Soontornmalai, Schaub, \& Fritschy, 2004; Nicchia et al., 2004, 2008b). 
Indeed, the lack of other dystrophins may also alter glial and endothelial structure and function. This is supported by the downregulation of AQP4 and increased vascular permeability in the Dp427-deficient mdx mouse (Nico et al., 2003), yet the underlying pathophysiological mechanisms are still unclear and perhaps indirect in this DMD mouse model (Nico et al., 2006). In the $\mathrm{mdx} 3 \mathrm{cv}$ mouse, which mutation impedes expression of all dystrophins, several studies pointed to the presence of low-level residual expression of dystrophin (Li, Yue, \& Duan, 2008; 2010) and upregulation of utrophin paralogues (Culligan, Glover, Dowling, \& Ohlendieck, 2001), which might participate to compensatory mechanisms (e.g., Vaillend \& Ungerer, 1999). Pioneer studies in the Dp71-null mouse however helped to specify the localization of Dp71 in the endfeet of radial glial cells, such as the Müller glial cells in the retina (Dalloz et al., 2003) and in the Bergmann glial cells in the cerebellum (Nicchia, Rossi, Nudel, Svelto, \& Frigeri, 2008a). In the present study, we confirmed the expression of Dp71 along the walls of capillaries in the molecular cell layer (MCL) and along the glia limitans of the cerebellum, i.e. in the endfeet of Bergmann glial cells. We further demonstrated a similar subcellular localization in the perivascular astrocyte endfeet in the hippocampal and cortical layers. Dp71 immunostaining did not overlap with the endothelial marker lectin, thus confirming its localization at the membrane of glial endfeet in face of vascular endothelial cells.

In the cerebellum, there was a residual expression of AQP4 in the granular cell layer (GCL) and in the white matter, in which no dystrophin could be detected in WT mice with our panspecific antibody. This is in agreement with a previous study performed in the same mouse model (Nicchia, Rossi, Nudel, Svelto, \& Frigeri, 2008a), demonstrating that Dp71 deficiency primarily impacts expression of the two main AQP4 isoforms involved in the formation of large orthogonal arrays of particles (OAPs) in the perivascular glial endfeet, AQP4-M1 and AQP4-M23, while distinct pools of AQP4 composing smaller OAPs in GCL were unaffected and therefore considered to be Dp71-independent pools. Here our quantifications confirmed that the Dp71-independent pool of AQP4 is fully maintained in GCL and white matter, with a partial overlap of AQP4 IR with GFAP-positive processes in GCL, likely corresponding to velate astrocytes (Nicchia, Rossi, Nudel, Svelto, \& Frigeri, 2008a). In the cerebellar lobules, Dp71 is required for AQP4 clustering in the distal glial endfeet that shield the microvasculature of the blood-brain barrier (BBB) and support water homeostasis. On the other hand, Dp71-independent pools of AQP4 and AQP4ex in protoplasmic astrocytes of the GCL might play a role in neuronal activity, while in fibrous astrocytes of the white matter 
they might contribute to the regulation of sodium and potassium concentration at the level of the nodes of Ranvier of myelinated fibers (Nico et al., 2002; Stavale et al., 2013; Wang \& Bordey, 2008).

Importantly, even if AQP4 expression was drastically reduced along capillaries in the MCL, it was not completely abolished by the loss of Dp71. We used semi-quantitative approaches to estimate the amount of residual AQP4 expression in perivascular glial endfeet, either with confocal image analysis of AQP4 IR along vascular walls in cerebellar sections, or with electron microscopic analysis of immunogold labeling of AQP4 channels at the glial endfoot membrane contacting the basal lamina surrounding capillaries. Both methods detected a $30 \%$ residual expression of AQP4 channels, thus demonstrating a partial loss of AQP4 polarized expression in cerebellar Bergmann glial cells. Likewise, confocal image analysis revealed a $30-40 \%$ residual expression of AQP4 in astrocyte endfeet adjacent to capillaries in the dendritic areas of the cornu ammonis 1 (CA1) hippocampal subfield (stratum oriens and stratum radiatum). AQP4 polarized expression was thus partially preserved in perivascular astrocytes of this forebrain structure. This was confirmed by our study of forebrain purified gliovascular units, which showed a residual expression of AQP4 characterized by punctate staining along capillary walls as compared to the continuous staining found in capillaries from WT mice.

In the cerebellar and hippocampal layers that showed a $30 \%$ residual expression of AQP4, the $\beta$-dystroglycan IR was reduced by about $50-60 \%$ along capillaries, while that of $\alpha 1-$ syntrophin was undetectable. Comparable observations were made in cortical layers. The alteration of $\beta$-dystroglycan and AQP4 distribution support the current hypothesis that Dp71 is the main dystrophin responsible for anchoring AQP4 and assembling the DAPC at the membrane of brain perivascular glial endfeet (Amiry-Moghaddam, Frydenlund, \& Ottersen, 2004; Neely et al., 2001). Most strikingly, Dp71 appears to be required for $\alpha 1$-syntrophin expression and distribution in the glial endfeet. The $\alpha 1$-syntrophin isoform is a major determinant of OAP size at the glial-vascular interface (Hoddevik et al., 2017), owing to the critical interactions between the PDZ domains of these two proteins (Adams, Mueller, \& Froehner, 2001). It has been suggested that a parallel reduction in AQP4 and $\alpha$-syntrophin occurs at the perivascular level in mice lacking Dp71 (Nicchia, Rossi, Nudel, Svelto, \& Frigeri, 2008a). However, this was not found in the present study, as $\alpha 1$-syntrophin was undetectable while AQP4 showed a 30\% residual expression. Interestingly, the ratio of expression levels for M1 and M23 isoforms was reduced in forebrain purified gliovascular 
units from Dp71-null mice compared to WT mice, suggesting a less important impact of Dp71 loss on M23 expression. This seems in line with other studies showing that some AQP4 polarization could be maintained in macroglia in the absence of $\alpha 1$-syntrophin (Enger et al., 2012) and that a selective residual immobilization of the M23 isoform may occur following astrocyte transfection with fusion proteins lacking the PDZ-binding domain to $\alpha 1$-syntrophin (Smith, Jin, Ratelade, \& Verkman, 2014).

Other proteins interacting with the DAPC have been involved in the clustering of AQP4 and formation of OAPs, such as $\beta$-dystroglycan (Noell et al., 2011), which expression is only partly affected in Dp71-null mice, $\alpha$-dystrobrevin (Bragg, Das, \& Froehner, 2010; Lien et al., 2012) or AQP4ex (De Bellis et al., 2017; Palazzo et al., 2019). Our present results show that Dp71 loss differently alters the expression of distinct DAPs, some of which might contribute to maintain a residual expression of AQP4 in perivascular domains. We showed the presence of some dystrophin paralogs, such as utrophins, in hippocampal capillaries, which might participate to putative compensation. However, it has been shown that utrophin-gene products are expressed in endothelial cells forming the capillaries, not in the perivascular glial cell endfeet (Haenggi, Soontornmalai, Schaub, \& Fritschy, 2004; Knuesel et al., 2000; Perronnet \& Vaillend, 2010; Perronnet et al., 2012) and utrophins did not appear to be upregulated in Dp71-null mice. Moreover, no dystrophin IR was detected in purified forebrain capillaries or in capillaries analyzed in tissue sections, suggesting that other dystrophins did not compensate for Dp71 loss to maintain residual AQP4 expression in perivascular domains.

Interestingly, we found that the relative expression levels of AQP4 and $\beta$-dystroglycan in the stratum lacunosum moleculare (SLM) were comparable between Dp71-null and WT mice, even though $\alpha 1$-syntrophin was also absent of this layer. The SLM is a specific layer of the hippocampus that contains the hippocampal fissure separating the dendritic layers of CA1 and dentate gyrus. Heterogeneous expression of AQP4 in brain tissue parenchyma and neuropil of selective laminar regions was reported by others, particularly in the SLM where AQP4 shows its highest hippocampal levels, in marked contrast with the uniformly distributed staining along blood vessels throughout the hippocampus (Hubbard, Hsu, Seldin, \& Binder, 2015). Besides the diffuse AQP4 staining in this layer, we found an intense staining for AQP4 around large-diameter blood vessels, likely corresponding to arterioles and precapillary arterioles, which are known to be scattered along the hippocampal fissure in the SLM. In both WT and Dp71-null mice, AQP4 IR was in GFAP-positive domains surrounding these largediameter vessels, indicating a glial expression. Likewise, we also found a similar pattern of 
expression for AQP4 and $\beta$-dystroglycan in cortical layers, characterized by a drastic reduction of pericapillary expression but preserved polarization around the pial artery and penetrating cortical arterioles in Dp71-null mice. The AQP4ex isoform also showed a similar pattern of expression, being polarized around both capillaries and large vessels in WT mice, while having a preserved expression selectively around larger vessels in the cerebellum (glia limitans), hippocampus and cortex of the Dp71-null mouse. This confirms that AQP4ex is crucial for anchoring of perivascular AQP4 in capillaries as reported by others (Palazzo et al., 2019). We also showed that some utrophin-gene products could be expressed in endothelial as well as glial compartments surrounding arterioles, suggesting a putative involvement in AQP4 residual expression in large vessels. Dystrophin expression was also detected in these domains, as well as in other cellular domains between the vessel subluminal region and GFAP-positive glial endfeet. We demonstrated that this latter staining corresponded to expression of the full-length Dp427 dystrophin in the smooth muscles of arterioles and in the largest segments of precapillary arterioles, as suggested earlier (Rauch et al., 2012).

Expression of a dystrophin-gene product in endothelial cells within skeletal muscles has been previously suggested (Palladino et al., 2013). In the present study, Dp427 was not detected in brain endothelial cells using a specific monoclonal antibody, while an IR signal was found using a polyclonal antibody directed against the C-terminal of dystrophins. Staining with this latter antibody was also detected in Dp71-null mice, in both lectin-positive cells and as punctate IR in GFAP-positive elements, around arterioles of the hippocampal SLM. This suggests that another brain dystrophin, not Dp71 or Dp427, was expressed in endothelial cells and glial endfeet around precapillary arterioles. Since Dp260 and Dp116 are believed to be selectively expressed in retina and peripheral nerve, respectively, it follows that Dp140 is a putative candidate that could contribute to the maintenance of AQP4 expression in large brain vessels. Dp140 has a strong expression during embryonic development and is expressed at low levels in adult brain tissues (Morris, Simmons, \& Nguyen, 1995; Soutou et al., 2019). Its cellular distribution is still unclear but it has been detected in brain blood vessels in a seminal study (Lidov, Selig, \& Kunkel, 1995). Moreover, it was previously reported that Dp140 could show ectopic induction in adult brain structures of Dp71-null mice (Benabdesselam et al., 2010; 2012).

In summary, a selective deficiency in Dp71 was associated with a drastic reduction of the polarized distribution of AQP4 channels in perivascular glial endfeet in both cerebellum and forebrain regions (hippocampus, cortex). Nevertheless, there was a residual expression of 
AQP4 and $\beta$-dystroglycan in dystrophin-negative glial endfeet surrounding capillaries, which therefore did not depend on compensatory mechanisms involving other dystrophin-gene products. In contrast, we also show that hippocampal precapillary arterioles of Dp71-null mice express Dp427 in vascular smooth muscle, which may likely protect arterioles against injuries (Rauch et al., 2012), while other putative dystrophin- or utrophin-gene product may contribute to the partial maintenance of AQP4 channels in arteriole-associated glial endfeet.

Our present data stoke the debate on the functions of distinct pools of AQP4 distributed in separate cells and brain regions in relation with mechanisms underlying potassium homeostasis and excitability mainly in the grey matter, while water homeostasis, astrogliosis, fluid movements ("glymphatic" circulation) and brain waste turnover largely take place in the white matter. At the perivascular level, the degree of AQP4 polarization seems comparable for brain capillaries and arterioles (Eidsvaag, Enger, Hansson, Eide, \& Nagelhus, 2017). However, we demonstrate here that it depends on Dp71 in capillaries, but not in arterioles. Although controversial, the glymphatic concept attributes distinct but interconnected functions to arterioles and capillaries. The cerebrospinal fluid (CSF) enters the brain along penetrating arterioles, exchanges with interstitial fluid (ISF) and exits along draining veins. It has been proposed that CSF diffuse through brain parenchyma while interstitial waste products circulating along perivascular spaces are removed along the entire vascular network by paravascular clearance pathways, possibly driven by arterial pulsations. Exchange of fluid suitable for the optimal function of neurons and glia, as well as waste removal from paravascular spaces, take place at the level of the neurovascular unit of capillaries. This process is likely dependent on astrocytic endfeet and water channels because they regulate the width of the paravascular spaces, which may be critical in presence of brain edema (Abbott, Pizzo, Preston, Janigro, \& Thorne, 2018; Rosic et al., 2019). In Dp71-null mice, the drastically reduced expression of AQP4 and AQP4ex around capillaries may significantly impede water and ion homeostasis in brain white matter. This might result in swelling of astrocyte endfeet, leading to partial closure of paravascular spaces, delayed perivascular drainage of interstitial solutes and neurogliovascular dysfunction. However, the unaltered polarization of AQP4 channels around large-caliber vessels involved in the regulation of large-volume fluid flows likely preserves fast clearance of waste products by peri-arterial drainage as well as efficient resorption of putative edema and inflammation (Köferl et al., 2014; Rosic et al., 2019). 
A loss of the polarized expression of AQP4 in macroglial cells is a feature of several pathologies beyond dystrophinopathies, including epilepsy (Eid et al., 2005), Alzheimer's disease (Yang et al., 2011) and ischemic strokes (Frydenlund et al., 2006). A better understanding of the molecular mechanisms underlying defects in AQP4 polarized distribution in macroglial cells is therefore important for a range of clinical conditions. The present mouse model may provide new interesting outcome measures caused by partial AQP4 delocalization. Although the Dp71-null mouse clearly cannot recapitulate the phenotypes displayed by AQP4 full knock-out models, it has a complete loss of $\alpha$-syntrophin, a major determinant of gliovascular functions. This mouse model may therefore be useful to better understand the basis and role of bidirectional water flow between blood and brain (AmiryMoghaddam et al., 2003a), potassium homeostasis (Amiry-Moghaddam et al., 2003b), risk factors for cytotoxic edema (Amiry-Moghaddam, Frydenlund, \& Ottersen, 2004; Hoddevik et al., 2017; Papadopoulos \& Verkman, 2005) and BBB function (Fukuda \& Badaut, 2012; Vacca et al., 2014; Wolburg-Buchholz et al., 2009). Future studies will determine whether such altered mechanisms participate to the neurophysiological and cognitive disturbances associated with Dp71 loss in DMD.

\section{REFERENCES}

Abbott, N. J., Pizzo, M. E., Preston, J. E., Janigro, D., \& Thorne, R. G. (2018). The role of brain barriers in fluid movement in the CNS: is there a 'glymphatic' system? Acta Neuropathologica, 135(3), 387-407. https://doi.org/10.1007/s00401-018-1812-4.

Adams, M. E., Mueller, H. A., \& Froehner, S. C. (2001). In vivo requirement of the alphasyntrophin PDZ domain for the sarcolemmal localization of nNOS and aquaporin-4. The Journal of Cell Biology, 155(1), 113-22. https://doi.org/10.1083/jcb.200106158.

Amiry-Moghaddam, M., Hoddevik, E. H., \& Ottersen, O. P. (2010). Aquaporins: multifarious roles in brain. Neuroscience, 168(4), 859-61. doi: 10.1016/j.neuroscience.2010.04.071.

Amiry-Moghaddam, M., Frydenlund, D. S., \& Ottersen, O. P. (2004). Anchoring of aquaporin-4 in brain: molecular mechanisms and implications for the physiology and pathophysiology of water transport. Neuroscience, 129(4), 999-1010. https://doi.org/10.1016/j.neuroscience.2004.08.049.

Amiry-Moghaddam, M., Otsuka, T., Hurn, P. D., Traystman, R. J., Haug, F. M., Froehner, S. C., ... Bhardwaj, A. (2003a). An alpha-syntrophin-dependent pool of AQP4 in astroglial 
end-feet confers bidirectional water flow between blood and brain. Proceedings of the National Academy of Sciences of the United States of America, 100(4), 2106-11. https://doi.org/10.1073/pnas.0437946100.

Amiry-Moghaddam, M., Williamson, A., Palomba, M., Eid, T., de Lanerolle, N. C., Nagelhus, E. A., ... Ottersen, O. P. (2003b). Delayed K+ clearance associated with aquaporin-4 mislocalization: phenotypic defects in brains of alpha-syntrophin-null mice. Proceedings of the National Academy of Sciences of the United States of America, 100(23), 13615-20. https://doi.org/10.1073/pnas.2336064100.

Aragón, J., González-Reyes, M., Romo-Yáñez, J., Vacca, O., Aguilar-González, G., Rendón, A., ... Montañez, C. (2018). Dystrophin Dp71 Isoforms Are Differentially Expressed in the Mouse Brain and Retina: Report of New Alternative Splicing and a Novel Nomenclature for Dp71 Isoforms. Molecular Neurobiology, 55(2), 1376-86. https://doi.org/10.1007/s12035-017-0405-x.

Austin, R. C., Morris, G. E., Howard, P. L., Klamut, H. J., \& Ray, P. N. (2000). Expression and synthesis of alternatively spliced variants of Dp71 in adult human brain. Neuromuscular Disorders, 10(3), 187-93. https://doi.org/10.1016/s0960-8966(99)00105-4.

Barboni, M. T. S., Vaillend, C., Joachimsthaler, A., Liber, A. M. P., Khabou, H., Roux, M. J., ... Kremers, J. (2020). Rescue of Defective Electroretinographic Responses in Dp71-Null Mice With AAV-Mediated Reexpression of Dp71. Investigative Ophthalmology \& Visual Science, 61(2), 11. https://doi.org/10.1167/iovs.61.2.11.

Benabdesselam, R., Dorbani-Mamine, L., Benmessaoud-Mesbah, O., Rendon, A., MhaoutyKodja, S., \& Hardin-Pouzet, H. (2012). Dp71 gene disruption alters the composition of the dystrophin-associated protein complex and neuronal nitric oxide synthase expression in the hypothalamic supraoptic and paraventricular nuclei. The Journal of Endocrinology, 213(3), 239-49. https://doi.org/10.1530/JOE-12-0066.

Benabdesselam, R., Sene, A., Raison, D., Benmessaoud-Mesbah, O., Ayad, G., Mornet, D., ... Dorbani-Mamine, L. (2010). A deficit of brain dystrophin 71 impairs hypothalamic osmostat. Journal of Neuroscience Research, 88(2), 324-34. https://doi.org/10.1002/jnr.22198.

Blauth, K., Soltys, J., Matschulat, A., Reiter, C. R., Ritchie, A., Baird, N. L., .. Owens, G. P. (2015). Antibodies produced by clonally expanded plasma cells in multiple sclerosis cerebrospinal fluid cause demyelination of spinal cord explants. Acta Neuropathologica, 130(6), 765-81. https://doi.org/10.1007/s00401-015-1500-6. 
Boulay, A. C., Saubaméa, B., Declèves, X., \& Cohen-Salmon, M. (2015). Purification of Mouse Brain Vessels. Journal of visualized experiments : Journal of Visualized Experiments, 105, e53208. https://doi.org/10.3791/53208.

Bragg, A. D., Das, S. S., \& Froehner, S. C. (2010). Dystrophin-associated protein scaffolding in brain requires alpha-dystrobrevin. Neuroreport, 21(10), 695-99. https://doi.org/10.1097/WNR.0b013e32833b0a3b.

Chaussenot, R., Amar, M., Fossier, P., \& Vaillend, C. (2019). Dp71-Dystrophin Deficiency Alters Prefrontal Cortex Excitation-Inhibition Balance and Executive Functions. Molecular Neurobiology, 56(4), 2670-84. https://doi.org/10.1007/s12035-018-1259-6.

Culligan, K., Glover, L., Dowling, P., \& Ohlendieck, K. (2001). Brain dystrophinglycoprotein complex: persistent expression of beta-dystroglycan, impaired oligomerization of Dp71 and up-regulation of utrophins in animal models of muscular dystrophy. BMC Cell Biology, 2, 2. https://doi.org/10.1186/1471-2121-2-2.

Dalloz, C., Sarig, R., Fort, P., Yaffe, D., Bordais, A., Pannicke, T., ... Rendon, A. (2003). Targeted inactivation of dystrophin gene product Dp71: phenotypic impact in mouse retina. Human Molecular Genetics, 12(13), 1543-54. https://doi.org/10.1093/hmg/ddg170.

Daoud, F., Angeard, N., Demerre, B., Martie, I., Benyaou, R., Leturcq, F., ... Chelly, J. (2009a). Analysis of Dp71 contribution in the severity of mental retardation through comparison of Duchenne and Becker patients differing by mutation consequences on Dp71 expression. Human Molecular Genetics, 18(20), 3779-94. https://doi.org/10.1093/hmg/ddp320.

Daoud, F., Candelario-Martínez, A., Billard, J. M., Avital, A., Khelfaoui, M., Rozenvald, Y., ... Vaillend, C. (2009b). Role of mental retardation associated dystrophin-gene product Dp71 in excitatory synapse organization, synaptic plasticity and behavioral functions. PLoS One, 4(8), e6574. https://doi.org/10.1371/journal.pone.0006574.

De Bellis, M., Pisani, F., Mola, M. G., Rosito, S., Simone, L., Buccoliero, C., ... Frigeri, A. (2017). Translational readthrough generates new astrocyte AQP4 isoforms that modulate supramolecular clustering, glial endfeet localization, and water transport. Glia, 65(5), 790803. https://doi.org/10.1002/glia.23126.

De Brouwer, A. P., Nabuurs, S. B., Verhaart, I. E., Oudakker, A. R., Hordijk, R., Yntema, H. G., ... Kleefstra, T. (2014). A 3-base pair deletion, c.9711_9713del, in DMD results in intellectual disability without muscular dystrophy. European Journal of Human Genetics, 22(4), 480-5. https://doi.org/10.1038/ejhg.2013.169. 
Desguerre, I., Christov, C., Mayer, M., Zeller, R., Becane, H. M., Bastuji-Garin, S., ... Gherardi, R. K. (2009). Clinical heterogeneity of Duchenne muscular dystrophy (DMD): definition of sub-phenotypes and predictive criteria by long-term follow-up. PLoS One, 4(2), e4347. https://doi.org/10.1371/journal.pone.0004347.

Eid, T., Lee, T. S., Thomas, M. J., Amiry-Moghaddam, M., Bjørnsen, L. P., Spencer, D. D., ... de Lanerolle, N. C. (2005). Loss of perivascular aquaporin 4 may underlie deficient water and $\mathrm{K}+$ homeostasis in the human epileptogenic hippocampus. Proceedings of the National Academy of Sciences of the United States of America, 102(4), 1193-98. https://doi.org/10.1073/pnas.0409308102.

Eidsvaag, V. A., Enger, R., Hansson, H. A., Eide, P. K., \& Nagelhus, E. A. (2017). Human and mouse cortical astrocytes differ in aquaporin-4 polarization toward microvessels. Glia, 65(6), 964-73. https://doi.org/10.1002/glia.23138.

El Mathari, B., Sene, A., Charles-Messance, H., Vacca, O., Guillonneau, X., Grepin, C., ... Tadayoni, R. (2015). Dystrophin Dp71 gene deletion induces retinal vascular inflammation and capillary degeneration. Human Molecular Genetics, 24(14), 3939-47. https://doi.org/10.1093/hmg/ddv132.

Enger, R., Gundersen, G. A., Haj-Yasein, N. N., Eilert-Olsen, M., Thoren, A. E., Vindedal, G. F., ... Nagelhus, E. A. (2012). Molecular scaffolds underpinning macroglial polarization: an analysis of retinal Müller cells and brain astrocytes in mouse. Glia, 60(12), 2018-26. https://doi.org/10.1002/glia.22416.

Farmer, W. T., Abrahamsson, T., Chierzi, S., Lui, C., Zaelzer, C., Jones, E. V., ... Murai, K. K. (2016). Neurons diversify astrocytes in the adult brain through sonic hedgehog signaling. Science, 351(6275), 849-54. https://doi.org/10.1126/science.aab3103.

Frigeri, A., Nicchia, G. P., Nico, B., Quondamatteo, F., Herken, R., Roncali, L., \& Svelto, M. (2001). Aquaporin-4 deficiency in skeletal muscle and brain of dystrophic mdx mice. The FASEB Journal, 15(1):90-8. https://doi.org/10.1096/fj.00-0260com.

Frydenlund, D. S., Bhardwaj, A., Otsuka, T., Mylonakou, M. N., Yasumura, T., Davidson, K. G., ... Amiry-Moghaddam, M. (2006). Temporary loss of perivascular aquaporin-4 in neocortex after transient middle cerebral artery occlusion in mice. Proceedings of the National Academy of Sciences of the United States of America, 103(36), 13532-6. https://doi.org/10.1073/pnas.0605796103.

Fukuda, A. M., \& Badaut, J. (2012). Aquaporin 4: a player in cerebral edema and neuroinflammation. Journal of Neuroinflammation, 9, 279. https://doi.org/10.1186/17422094-9-279. 
Haenggi, T., Schaub, M. C., \& Fritschy, J. M. (2005). Molecular heterogeneity of the dystrophin-associated protein complex in the mouse kidney nephron: differential alterations in the absence of utrophin and dystrophin. Cell and Tissue Research, 319(2), 299-313. https://doi.org/10.1007/s00441-004-0999-y.

Haenggi, T., Soontornmalai, A., Schaub, M. C., \& Fritschy, J. M. (2004). The role of utrophin and Dp71 for assembly of different dystrophin-associated protein complexes (DPCs) in the choroid plexus and microvasculature of the brain. Neuroscience, 129(2), 403-13. https://doi.org/10.1016/j.neuroscience.2004.06.079.

Helleringer, R., Le Verger, D., Li, X., Izabelle, C., Chaussenot, R., Belmaati-Cherkaoui, M., ... Vaillend, C. (2018). Cerebellar synapse properties and cerebellum-dependent motor and non-motor performance in Dp71-null mice. Disease Models \& Mechanisms, 11, 7. https://doi.org/10.1242/dmm.033258.

Hoddevik, E. H., Khan, F. H., Rahmani, S., Ottersen, O. P., Boldt, H. B., \& AmiryMoghaddam, M. (2017). Factors determining the density of AQP4 water channel molecules at the brain-blood interface. Brain Structure \& Function, 222(4), 1753-66. https://doi.org/10.1007/s00429-016-1305-y.

Hubbard, J. A., Szu, J. I., \& Binder, D. K. (2018). The role of aquaporin-4 in synaptic plasticity, memory and disease. Brain Research Bulletin, 136, 118-29. https://doi.org/10.1016/j.brainresbull.2017.02.011.

Hubbard, J. A., Hsu, M. S., Seldin, M. M., \& Binder, D. K. (2015). Expression of the Astrocyte Water Channel Aquaporin-4 in the Mouse Brain. ASN Neuro, 7, 5. https://doi.org/10.1177/1759091415605486.

Inoue, M., Wakayama, Y., Liu, J. W., Murahashi, M., Shibuya, S., \& Oniki, H. (2002). Ultrastructural localization of aquaporin 4 and alpha1-syntrophin in the vascular feet of brain astrocytes. The Tohoku Journal of Experimental Medicine, 197(2):87-93. https://doi.org/10.1620/tjem.197.87.

Kawashima, H., Sueyoshi, S., Li, H., Yamamoto, K., \& Osawa, T. (1990). Carbohydrate binding specificities of several poly-N-acetyllactosamine-binding lectins. Glycoconjugate Journal, 7(4), 323-34. https://doi.org/10.1007/bf01073376.

Knuesel, I., Bornhauser, B. C., Zuellig, R. A., Heller, F., Schaub, M. C., \& Fritschy, J. M. (2000). Differential expression of utrophin and dystrophin in CNS neurons: an in situ hybridization and immunohistochemical study. The Journal of Comparative Neurology, 422(4), 594-611. https://doi.org/10.1002/1096-9861(20000710)422:4<594::aidcne8>3.0.co;2-q. 
Köferl, P., Hollborn, M., Rehak, J., Iandiev, I., Dukic-Stefanovic, S., Wiedemann, P., ... Rehak, M. (2014). Effects of arteriolar constriction on retinal gene expression and Müller cell responses in a rat model of branch retinal vein occlusion. Graefe's Archive for Clinical and Experimental Ophthalmology, 252(2), 257-65. https://doi.org/10.1007/s00417-0132532-z.

Kofuji, P., \& Newman, E. A. (2004). Potassium buffering in the central nervous system. Neuroscience, 129(4), 1045-56. https://doi.org/10.1016/j.neuroscience.2004.06.008.

Li, D., Yue, Y., \& Duan, D. (2010). Marginal level dystrophin expression improves clinical outcome in a strain of dystrophin/utrophin double knockout mice. PLoS One, 5(12), e15286. https://doi.org/10.1371/journal.pone.0015286.

Li, D., Yue, Y., \& Duan, D. (2008). Preservation of muscle force in Mdx3cv mice correlates with low-level expression of a near full-length dystrophin protein. The American Journal of Pathology, 172(5), 1332-41. https://doi.org/10.2353/ajpath.2008.071042.

Lidov, H. G., Selig, S., \& Kunkel, L. M. (1995). Dp140: a novel 140 kDa CNS transcript from the dystrophin locus. Human Molecular Genetics, 4(3), 329-35. https://doi.org/10.1093/hmg/4.3.329.

Lien, C. F., Mohanta, S. K., Frontczak-Baniewicz, M., Swinny, J. D., Zablocka, B., \& Górecki, D. C. (2012). Absence of glial $\alpha$-dystrobrevin causes abnormalities of the bloodbrain barrier and progressive brain edema. The Journal of Biological Chemistry, 287(49), 41374-85. https://doi.org/10.1074/jbc.M112.400044.

Morris, G. E., Simmons, C., \& Nguyen, T. M. (1995). Apo-dystrophins (Dp140 and Dp71) and dystrophin splicing isoforms in developing brain. Biochemical and Biophysical Research Communications, 215(1), 361-7. https://doi.org/10.1006/bbrc.1995.2474.

Naidoo, M., \& Anthony K. (2020). Dystrophin Dp71 and the Neuropathophysiology of Duchenne Muscular Dystrophy. Molecular Neurobiology, 57(3), 1748-67. https://doi.org/10.1007/s12035-019-01845-w.

Neely, J. D., Amiry-Moghaddam, M., Ottersen, O. P., Froehner, S. C., Agre, P., \& Adams, M. E. (2001). Syntrophin-dependent expression and localization of Aquaporin-4 water channel protein. Proceedings of the National Academy of Sciences of the United States of America, 98(24), 14108-13. https://doi.org/10.1073/pnas.241508198.

Nicchia, G. P., Rossi, A., Nudel, U., Svelto, M., \& Frigeri, A. (2008a). Dystrophin-dependent and -independent AQP4 pools are expressed in the mouse brain. Glia, 56(8), 869-76. https://doi.org/10.1002/glia.20661. 
Nicchia, G. P., Cogotzi, L., Rossi, A., Basco, D., Brancaccio, A., Svelto, M., \& Frigeri, A. (2008b). Expression of multiple AQP4 pools in the plasma membrane and their association with the dystrophin complex. Journal of Neurochemistry, 105(6), 2156-65. https://doi.org/10.1111/j.1471-4159.2008.05302.x.

Nicchia, G. P., Nico, B., Camassa, L. M., Mola, M. G., Loh, N., Dermietzel, R., ... Frigeri, A. (2004). The role of aquaporin-4 in the blood-brain barrier development and integrity: studies in animal and cell culture models. Neuroscience, 129(4), 935-45. https://doi.org/10.1016/j.neuroscience.2004.07.055.

Nico, B., Corsi, P., Ria, R., Crivellato, E., Vacca, A., Roccaro, A. M., ... Roncali, L. (2006). Increased matrix-metalloproteinase- 2 and matrix-metalloproteinase- 9 expression in the brain of dystrophic $\mathrm{mdx}$ mouse. Neuroscience, 140(3), 835-48. https://doi.org/10.1016/j.neuroscience.2006.02.077.

Nico, B., Frigeri, A., Nicchia, G. P., Corsi, P., Ribatti, D., Quondamatteo, F., ... Roncali, L. (2003). Severe alterations of endothelial and glial cells in the blood-brain barrier of dystrophic mdx mice. Glia, 42(3), 235-51. https://doi.org/10.1002/glia.10216.

Nico, B., Ribatti, D., Frigeri, A., Nicchia, G. P., Corsi, P., Svelto, M., \& Roncali, L. (2002). Aquaporin-4 expression during development of the cerebellum. Cerebellum, 1(3), 207-12. https://doi.org/10.1080/14734220260418439.

Noell, S., Wolburg-Buchholz, K., Mack, A. F., Beedle, A. M., Satz, J. S., Campbell, K. P., ... Fallier-Becker, P. (2011). Evidence for a role of dystroglycan regulating the membrane architecture of astroglial endfeet. The European Journal of Neuroscience, 33, 2179-86. https://doi.org/10.1111/j.1460-9568.2011.07688.x.

Palazzo, C., Buccoliero, C., Mola, M. G., Abbrescia, P., Nicchia, G. P., Trojano, M., \& Frigeri, A. (2019). AQP4ex is crucial for the anchoring of AQP4 at the astrocyte end-feet and for neuromyelitis optica antibody binding. Acta Neuropathologica Communications, 7(1), 51. https://doi.org/10.1186/s40478-019-0707-5.

Palladino, M., Gatto, I., Neri, V., Straino, S., Smith, R. C., Silver, M., ... \& Pola, R. (2013). Angiogenic impairment of the vascular endothelium: a novel mechanism and potential therapeutic target in muscular dystrophy. Arteriosclerosis, Thrombosis, and Vascular Biology, 33(12), 2867-76. https://doi.org/10.1161/ATVBAHA.112.301172.

Papadopoulos, M. C., \& Verkman, A. S. (2005). Aquaporin-4 gene disruption in mice reduces brain swelling and mortality in pneumococcal meningitis. The Journal of Biological Chemistry, 280(14), 13906-12. https://doi.org/10.1074/jbc.M413627200. 
Paxinos, G., \& Franklin, K. B. J. (2001). The mouse brain in stereotaxic coordinates (2nd ed.). San Diego, CA: Academic Press.

Perronnet, C., Chagneau, C., Le Blanc, P., Samson-Desvignes, N., Mornet, D., Laroche, S., ... Vaillend, C. (2012). Upregulation of brain utrophin does not rescue behavioral alterations in dystrophin-deficient mice. Human Molecular Genetics, 21(10), 2263-76. https://doi.org/10.1093/hmg/dds047.

Perronnet, C., \& Vaillend, C. (2010). Dystrophins, utrophins, and associated scaffolding complexes: role in mammalian brain and implications for therapeutic strategies. Journal of Biomedicine \& Biotechnology, 2010, 849426. https://doi.org/10.1155/2010/849426.

Porter, G. A., Palade, G. E., \& Milici, A. J. (1990). Differential binding of the lectins Griffonia simplicifolia I and Lycopersicon esculentum to microvascular endothelium: organ-specific localization and partial glycoprotein characterization. European Journal of Cell Biology, 51(1), 85-95.

Puwarawuttipanit, W., Bragg, A. D., Frydenlund, D. S., Mylonakou, M. N., Nagelhus, E. A., Peters, M. F., ... Amiry-Moghaddam, M. (2006). Differential effect of alpha-syntrophin knockout on aquaporin-4 and Kir4.1 expression in retinal macroglial cells in mice. Neuroscience, 137(1), 165-75. https://doi.org/10.1016/j.neuroscience.2005.08.051.

Rauch, U., Shami, A., Zhang, F., Carmignac, V., Durbeej, M., \& Hultgårdh-Nilsson, A. (2012). Increased neointimal thickening in dystrophin-deficient mdx mice. PLoS One, 7(1), e29904. https://doi.org/10.1371/journal.pone.0029904.

Ricotti, V., Mandy, W. P., Scoto, M., Pane, M., Deconinck, N., Messina, S., ... Muntoni, F. (2016). Neurodevelopmental, emotional, and behavioural problems in Duchenne muscular dystrophy in relation to underlying dystrophin gene mutations. Developmental Medicine and Child Neurology, 58(1), 77-84. https://doi.org/10.1111/dmcn.12922.

Ricotti, V., Roberts, R. G., \& Muntoni, F. (2011). Dystrophin and the brain. Developmental Medicine and Child Neurology, 53(1), 12. https://doi.org/10.1111/j.14698749.2010.03836.x.

Rosic, B., Dukefoss, D. B., Åbjørsbråten, K. S., Tang, W., Jensen, V., Ottersen, O. P., ... Nagelhus, E. A. (2019). Aquaporin-4-independent volume dynamics of astroglial endfeet during cortical spreading depression. Glia, 67(6), 1113-21. https://doi.org/10.1002/glia.23604.

Sarig, R., Mezger-Lallemand, V., Gitelman, I., Davis, C., Fuchs, O., Yaffe, D., \& Nudel, U. (1999). Targeted inactivation of Dp71, the major non-muscle product of the DMD gene: 
differential activity of the Dp71 promoter during development. Human Molecular Genetics, 8(1), 1-10. https://doi.org/10.1093/hmg/8.1.1.

Sene, A., Tadayoni, R., Pannicke, T., Wurm, A., El Mathari, B., Benard, R., ... Rendon, A. (2009). Functional implication of Dp71 in osmoregulation and vascular permeability of the retina. PLoS One, 4(10), e7329. https://doi.org/10.1371/journal.pone.0007329.

Smith, A. J., Jin, B. J., Ratelade, J., \& Verkman, A. S. (2014). Aggregation state determines the localization and function of M1- and M23-aquaporin-4 in astrocytes. Journal of Cell Biology, 17, 204(4), 559-73. https://doi.org/10.1083/jcb.201308118.

Souttou, S., Benabdesselam, R., Siqueiros-Marquez, L., Sifi, M., Deliba, M., Vacca, O., ... Dorbani-Mamine, L. (2019). Expression and localization of dystrophins and $\beta$ dystroglycan in the hypothalamic supraoptic nuclei of rat from birth to adulthood. Acta Histochemica, 121(2), 218-26. https://doi.org/10.1016/j.acthis.2018.12.001.

Stavale, L. M., Soares, E. S., Mendonça, M. C., Irazusta, S. P., \& da Cruz Höfling, M. A. (2013). Temporal relationship between aquaporin-4 and glial fibrillary acidic protein in cerebellum of neonate and adult rats administered a BBB disrupting spider venom. Toxicon, 66, 37-46. https://doi.org/10.1016/j.toxicon.2013.01.026.

Tadayoni, R., Rendon, A., Soria-Jasso, L.E., \& Cisneros, B. (2012). Dystrophin Dp71: the smallest but multifunctional product of the Duchenne muscular dystrophy gene. Molecular Neurobiology, 45(1), 43-60. https://doi.org/10.1007/s12035-011-8218-9.

Vacca, O., Charles-Messance, H., El Mathari, B., Sene, A., Barbe, P., Fouquet, S., ... Rendon, A. (2016). AAV-mediated gene therapy in Dystrophin-Dp71 deficient mouse leads to blood-retinal barrier restoration and oedema reabsorption. Human Molecular Genetics, 25(14), 3070-79. https://doi.org/10.1093/hmg/ddw159.

Vacca, O., Darche, M., Schaffer, D. V., Flannery, J. G., Sahel, J. A., Rendon, A., \& Dalkara, D. (2014). AAV-mediated gene delivery in Dp71-null mouse model with compromised barriers. Glia, 62(3), 468-76. https://doi.org/10.1002/glia.22617.

Vaillend, C., Perronnet, C., Ros, C., Gruszczynski, C., Goyenvalle, A., Laroche, S., ... Peltekian, E. (2010). Rescue of a dystrophin-like protein by exon skipping in vivo restores GABAA-receptor clustering in the hippocampus of the mdx mouse. Molecular Therapy, 18(9), 1683-8. https://doi.org/10.1038/mt.2010.134.

Vaillend, C., \& Ungerer, A. (1999). Behavioral characterization of mdx3cv mice deficient in C-terminal dystrophins. Neuromuscular Disorders, 9(5), 296-304. https://doi.org/10.1016/s0960-8966(99)00029-2. 
Wang, D. D., \& Bordey, A. (2008). The astrocyte odyssey. Progress in Neurobiology, 86(4), 342-67. https://doi.org/10.1016/j.pneurobio.2008.09.015.

Wen, H., Nagelhus, E. A., Amiry-Moghaddam, M., Agre, P., Ottersen, O. P., \& Nielsen, S. (1999). Ontogeny of water transport in rat brain: postnatal expression of the aquaporin-4 water channel. The European Journal of Neuroscience, 11(3), 935-45. https://doi.org/10.1046/j.1460-9568.1999.00502.x.

Wolburg-Buchholz, K., Mack, A. F., Steiner, E., Pfeiffer, F., Engelhardt, B., \& Wolburg, H. (2009). Loss of astrocyte polarity marks blood-brain barrier impairment during experimental autoimmune encephalomyelitis. Acta Neuropathologica, 118(2), 219-33. https://doi.org/10.1007/s00401-009-0558-4.

Woo, J., Kim, J. E., Im, J. J., Lee, J., Jeong, H. S., Park, S., .. Lee, C. J. (2018). Astrocytic water channel aquaporin-4 modulates brain plasticity in both mice and humans: a potential gliogenetic mechanism underlying language-associated learning. Molecular Psychiatry, 23(4), 1021-30. https://doi.org/10.1038/mp.2017.113.

Yang, J., Lunde, L. K., Nuntagij, P., Oguchi, T., Camassa, L. M., Nilsson, L. N., ... Torp, R. (2011). Loss of astrocyte polarization in the tg-ArcSwe mouse model of Alzheimer's disease. Journal of Alzheimer's Disease, 27(4), 711-22. https://doi.org/10.3233/JAD-2011110725 .

\section{FIGURE LEGENDS}

FIGURE 1. Localization of Dp71 in hippocampus and cerebellum and characterization in Dp71-null mice. (A) Representative image-stack projections obtained by confocal laser scanning microscopy, showing dystrophin-IR revealed by the $\mathrm{H} 4$ anti-dystrophin antibody in hippocampus and cerebellum of WT and Dp71-null mice. In WT mice, IR was distributed along the walls of capillaries in all layers of the hippocampal Hamon's horn including the larger vessels of the SLM (arrows), while in the cerebellar vermis it was distributed at the level of capillaries as well as along the cerebellar glia limitans (GL). IR was virtually absent in Dp71-null mice, indicating it selectively reflected Dp71 expression. SP: stratum pyramidale, SR: stratum radiatum, SLM: stratum lacunosum moleculare, MCL: molecular cell layer, GL: Glia limitans, GCL: granular cell layer, WM: white matter. Scale bars: 100 $\mu \mathrm{m}$. (B) Merged triple immunofluorescence staining of Dp71 (red), endothelial marker lectin (green) and nuclear marker DAPI (blue). Both longitudinal (top panel, scale bar: $20 \mu \mathrm{m}$ ) and 
transversal views with $\mathrm{x} / \mathrm{y}$ orthogonal projections (below, scale bar: $10 \mu \mathrm{m}$ ) showed no overlap between Dp71-IR and lectin, confirming Dp71 expression in perivascular domains and its absence in Dp71-null mice.

FIGURE 2. Immunolocalization of AQP4 channels and DAPs in cerebellum. (A) Representative confocal image-stack projections (scale bars: $100 \mu \mathrm{m}$ ) showing AQP4-IR in all layers of the cerebellar vermis in WT mice, with strong perivascular signal in the MCL (arrowheads) and along the GL (arrows), while in Dp71-null mice AQP4-IR was drastically reduced along capillary walls of the MCL. In Dp71-null mice, a low-intensity signal was still detectable in some capillaries (arrowhead) and GL (arrows), while AQP4-IR was mostly preserved in WM and GCL. (B) Semi-quantitative analysis of AQP4 IR expressed as \% of WT in MCL ( $\mathrm{n}=4 \mathrm{WT}$ and 5 Dp71-null mice). Residual IR in perivascular domains of the MCL in Dp71-null mice was estimated 30\% of WT levels (*p<0.05). (C-D) Analysis of AQP4 channels in cerebellar MCL by immunogold electron microscopy. Sample micrographs from a WT mouse illustrate AQP4 immunogold labeling (arrows) in macroglial membrane domains surrounding the vascular endothelium of a capillary (C, scale bar: $200 \mathrm{~nm}$ ) and along the GL (D, scale bar: $500 \mathrm{~nm}$ ). Histograms show AQP4 density as mean number of beads per $\mu \mathrm{m}$ $(\mathrm{n}=2$ per genotype) along perivascular glial membranes (C; average of 18 capillary crosssections per genotype; > $290 \mu \mathrm{m}$ of membrane) and along the GL (D; > $270 \mu \mathrm{m}$ of membrane per genotype). Sections without primary antibody were used as control (Ctrl). E: endothelium; L: capillary lumen; G: glial endfoot; asterisk: basal lamina. (E-F) Confocal image-stack projections showing expression of the dystrophin-associated proteins (DAPs): $\beta$-dystroglycan ( $\beta$-DG; in E; scale bars: $80 \mu \mathrm{m})$ and $\alpha$-syntrophin $(\alpha$-SYN; in F; Scale bars: $100 \mu \mathrm{m})$. Histograms show quantification as \% of WT ( $\mathrm{n}=4 \mathrm{WT}$ and 5 Dp71-null mice). IR for $\beta$-DG (E) and $\alpha$-SYN (F) were distributed along capillary walls and GL in WT mice. Expression of $\beta$-DG was reduced by about $50 \%$ in Dp71-null mice $(* * p<0.01)$, whereas $\alpha$-SYN was completely absent in Dp71-null mice. MCL: molecular cell layer, GL: Glia limitans, GCL: granular cell layer, WM: white matter.

FIGURE 3. Immunolocalization of Dp71-associated proteins in hippocampus. (A-C) The IR for AQP4 (A), $\beta$-dystroglycan (B, $\beta$-DG) and $\alpha$-syntrophin $(\mathrm{C}, \alpha$-SYN) was distributed in perivascular domains surrounding capillaries (arrows) and arterioles in the SLM (arrowheads). Histograms show that expression of AQP4 and $\beta$-DG were significantly reduced in Dp71-null mice (black bars) compared to WT (white bars) in SO and SR layers, but not in the SLM, likely due to the residual expression seen in Dp71-null mice surrounding 
arterioles along the hippocampal fissure (arrowheads). The $\alpha-S Y N-I R$ was completely absent in Dp71-null mice in all layers (C). SO: stratum oriens, SP: stratum pyramidale, SR: stratum radiatum, SLM: stratum lacunosum moleculare. All histograms show the mean \pm SEM of 4 WT and 5 Dp71-null mice; IR is expressed as \% of WT levels; ${ }^{*} p<0.05$, significantly different from WT levels. Scale bars: $50 \mu \mathrm{m}$.

FIGURE 4. Immunolocalization of Dp71 and associated proteins in cortex. (A-D) The IR of dystrophins (A, DYS), $\beta$-dystroglycan (B, $\beta$-DG), $\alpha$-syntrophin (C, $\alpha$-SYN) and AQP4 (D) are shown in red; the endothelial marker (lectin) is green in overlays in B and D. All proteins were detected along the pial surface, penetrating arterioles and capillaries in WT mice. In Dp71-null mice, residual IR was detected for dystrophins (A), $\beta$-DG (B) and AQP4 (D, left panels), but not for $\alpha-S Y N(C)$, in the perivascular domains surrounding pial artery and penetrating arterioles (arrows; arteriole shown in inserts for $\beta$-DG). Faint residual IR around capillaries was seen in Dp71-null mice for DYS, $\beta$-DG and AQP4. Note that AQP4 IR was detected in both genotypes along the pial surface, including within the interhemispheric fissure (D, right panels). Scale bars: $50 \mu \mathrm{m}$ in A-C, $10 \mu \mathrm{m}$ in D.

FIGURE 5. Expression of distinct AQP4 isoforms in the forebrain. (A) Western blots showing immunodetection of AQP4 isoforms (M1, M23 and AQP4ex, as indicated) in purified forebrain gliovascular units (vessels of $20-100 \mu \mathrm{m}$ in diameter). Each lane is a pool of 3 distinct mouse samples; molecular weights are indicated on the left. Histograms on the right show quantification of total M1 and M23 isoforms, M1/M23 ratio and AQP4ex $\left({ }^{*} \mathrm{p}<0.05\right.$; significantly different from WT, $n=3$ pooled samples per genotype). (B) Immunolocalization of AQP4ex in hippocampus, cortex and cerebellum. AQP4ex IR (red) and endothelial marker (lectin, green in overlays) are shown in the three brain structures in WT and Dp71-null mice, as indicated. Note the loss of pericapillary IR in Dp71-null mice in all structures, while IR around large-caliber vessels was preserved (arrows). The insert in Dp71-null hippocampus shows that AQP4ex IR did not overlap with lectin around arterioles of the SLM in sections labeled with the two markers (zoom of a transversal view of one arteriole). Hippocampal layers: stratum pyramidale (SP), stratum radiatum (SR) and stratum lacunosum moleculare (SLM); cerebellar layers: molecular cell layer (MCL) and glia limitans (GL). Scale bars: $100 \mu \mathrm{m}$ in main images; $25 \mu \mathrm{m}$ in the insert of Dp71-null hippocampus; $45 \mu \mathrm{m}$ in inserts of cortex and cerebellum. 
FIGURE 6. Subcellular localization of AQP4 and associated proteins in capillaries and arterioles. (A-C) IR for AQP4 (A), $\beta$-dystroglycan ( $\beta$-DG, B) and dystrophins (DYS, C) in purified gliovascular units from forebrain capillaries $(5-10 \mu \mathrm{m}$ in diameter) of WT and Dp71null mice. The nuclear and endothelial markers, DAPI and Lectin, are shown in dark blue and green, respectively. (D-G) IR signals (red) for AQP4 (D), $\beta$-DG (E), utrophins (F, UTRN) and dystrophins (G, DYS) in arterioles (diameter: $\geq 30 \mu \mathrm{m})$ of the hippocampal SLM region in tissue sections. Multiple staining for lectin (green), GFAP (cyan) and nuclei (DAPI, dark blue) are indicated as top panels. The arrows in G show dystrophin IR in GFAP-positive elements surrounding arterioles in Dp71-null mice. Scale bars: $15 \mu \mathrm{m}$ in A-C, $10 \mu \mathrm{m}$ in $\mathrm{D}, \mathrm{E}, \mathrm{G}$, and $25 \mu \mathrm{m}$ in $\mathrm{F}$.

FIGURE 7. Immunolocalization of Dp427 dystrophin in the vascular compartment. (A) Western blots showing expression of dystrophins (Dp427, Dp140, Dp71) and $\beta$-actin (loading control) in WT and Dp71-null mice ( $\mathrm{n}=6$ per genotype). The histogram shows data expressed as the mean fold change ( \pm SEM) compared to WT. Dp427 expression was significantly higher in Dp71-null mice compared to WT. ${ }^{*} \mathrm{p}<0.05$; ${ }^{*} \mathrm{p}<0.01$; significantly different from WT. (B) Detection of Dp427 (magenta), GFAP (cyan) and lectin staining (green) in arterioles (diameter: $\geq 30 \mu \mathrm{m}$ ) of the hippocampal stratum lacunosum moleculare (SLM) in tissue sections. (C) The upper panels show double labeling of arterioles, precapillary arterioles and capillaries (asterisk in upper left image) with smooth-muscle marker $\alpha$-SMA (red) and lectin (green) in a hippocampal tissue section. Note that overlapping IR (yellow-orange) is only present in large diameter vascular elements (i.e., arterioles and initial segment of precapillary arterioles). The lower panels show Dp427 IR (white) in the same vessels; Dp427 IR was restricted to the large-diameter precapillary arterioles, not in smaller precapillary arterioles (arrows) or capillaries (asterisk). (D) Detection of the smooth-muscle marker $\alpha$-SMA (red), Dp427 (white) and lectin (green) in purified arterioles. Note that Dp427 and $\alpha$-SMA IR is localized in the same vascular subdomains but does not overlap with the IR of endothelial marker lectin (arrow). Scale bars: $10 \mu \mathrm{m}$ in B, $15 \mu \mathrm{m}$ in C, $20 \mu \mathrm{m}$ in D. 
A
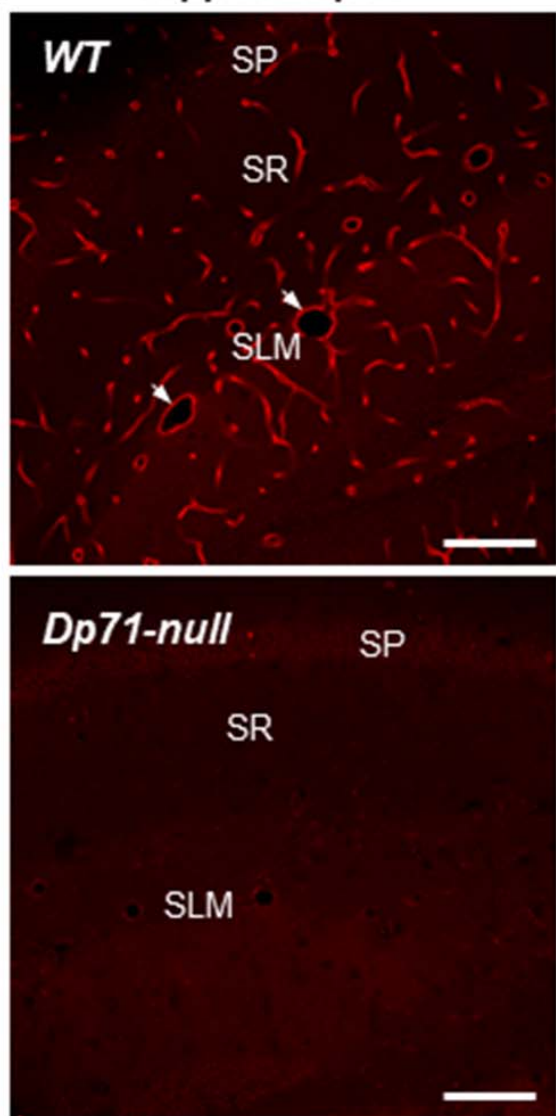

Cerebellum

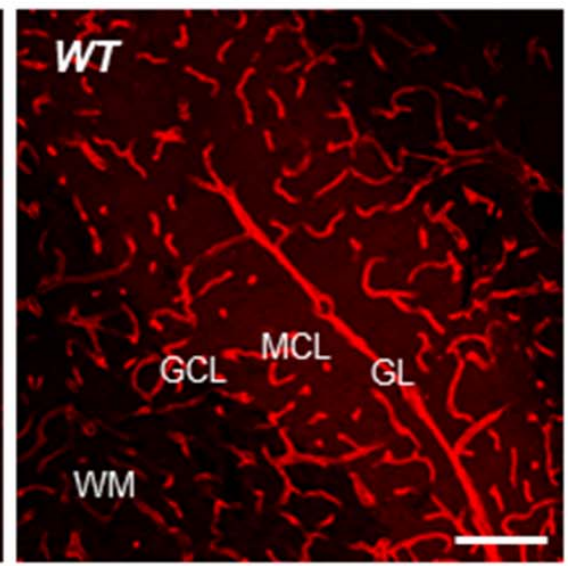

Dp71-null

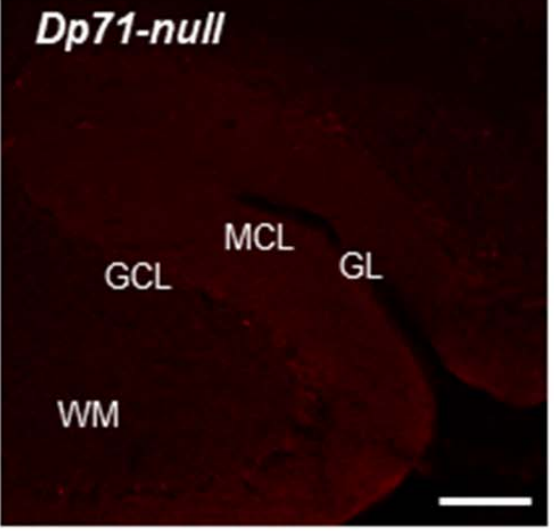

B
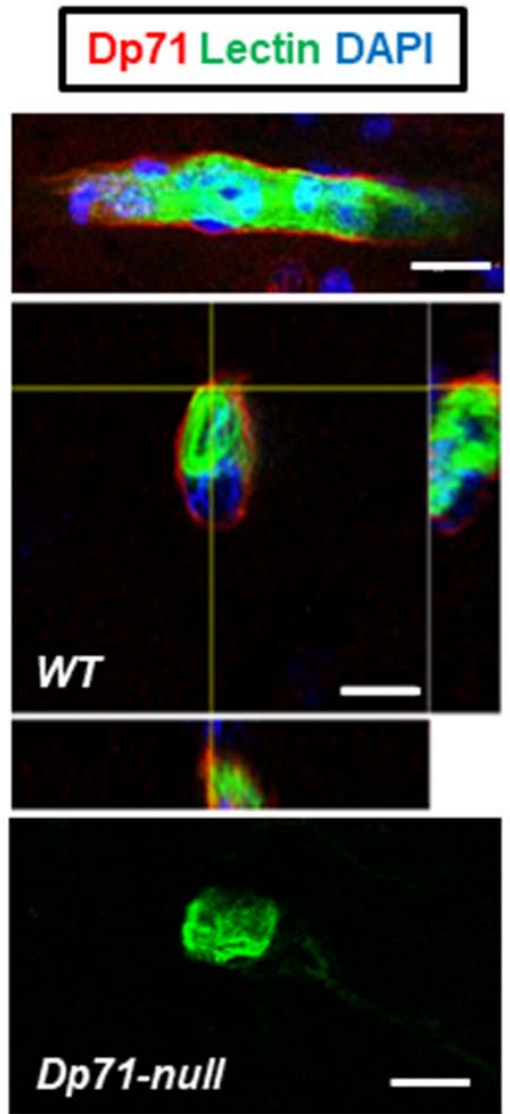

FIGURE 1. Localization of Dp71 in hippocampus and cerebellum and characterization in Dp71-null mice. (A) Representative image-stack projections obtained by confocal laser scanning microscopy, showing dystrophin-IR revealed by the $\mathrm{H} 4$ anti-dystrophin antibody in hippocampus and cerebellum of WT and Dp71-null mice. In WT mice, IR was distributed along the walls of capillaries in all layers of the hippocampal Hamon's horn including the larger vessels of the SLM (arrow), while in the cerebellar vermis it was distributed at the level of capillaries as well as along the cerebellar glia limitans (GL). IR was virtually absent in Dp71-null mice, indicating it selectively reflected Dp71 expression. SP: stratum pyramidale, SR: stratum radiatum, SLM: stratum lacunosum moleculare, MCL: molecular cell layer, GL: Glia limitans, GCL: granular cell layer, WM: white matter. Scale bars: $100 \mu$ m. (B) Merged triple immunofluorescence staining of Dp71 (red), endothelial marker lectin (green) and nuclear marker DAPI (blue). Both longitudinal (top panel, scale bar: $20 \mu \mathrm{m}$ ) and transversal views with $\mathrm{x} / \mathrm{y}$ orthogonal projections (below, scale bar: $10 \mu \mathrm{m}$ ) showed no overlap between Dp71-IR and lectin, confirming Dp71 expression in perivascular domains and its absence in Dp71-null mice. 

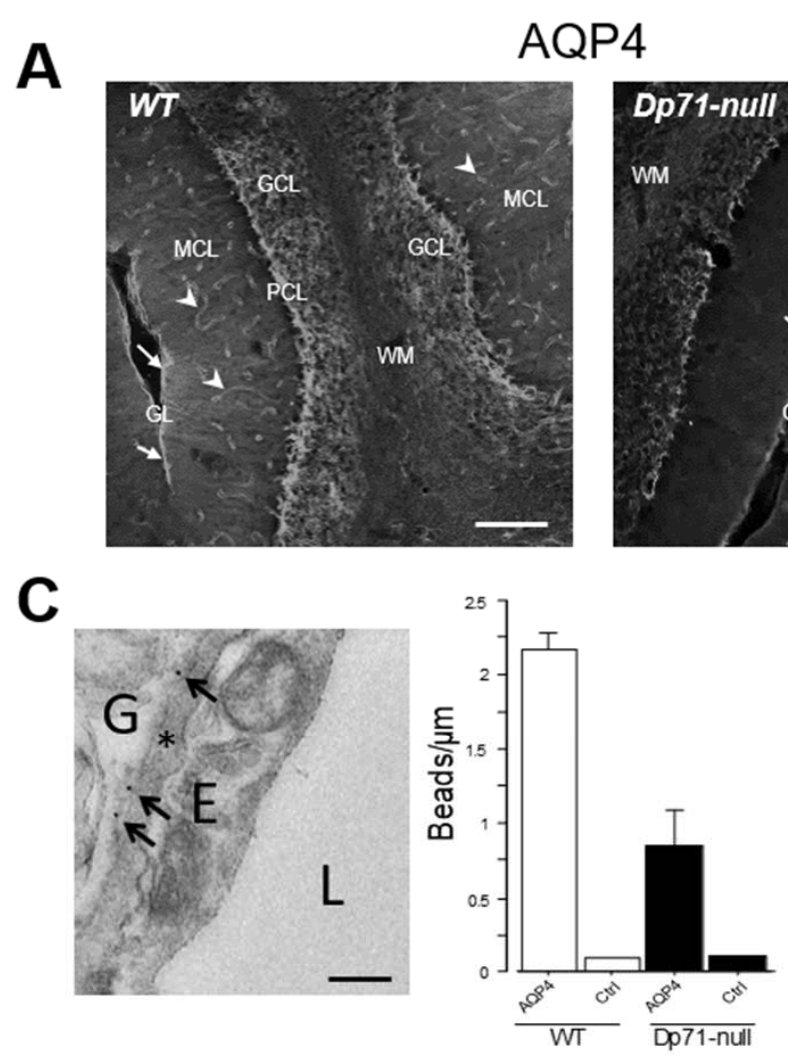

B

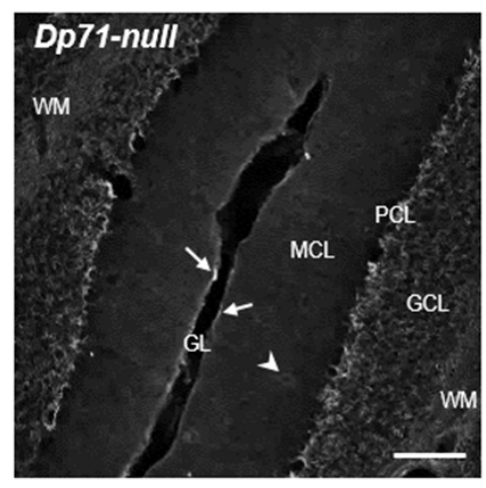

D

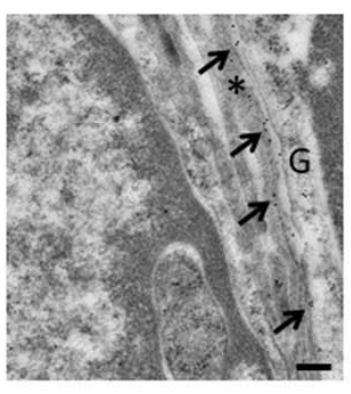

Quantification of AQP4 IR in the MCL

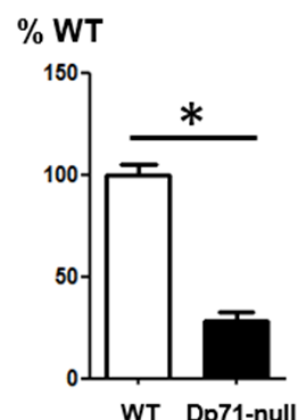

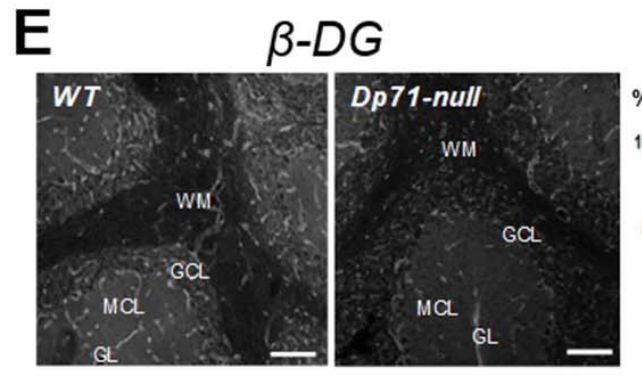

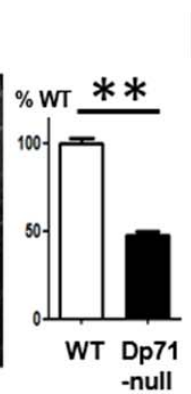

$\mathbf{F}$
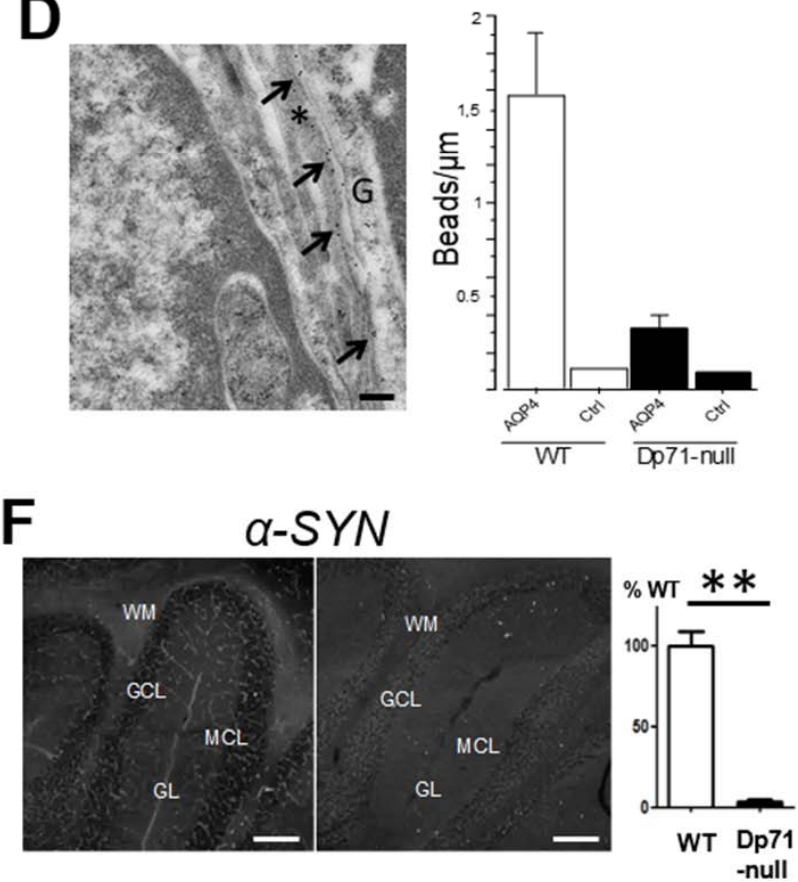

FIGURE 2. Immunolocalization of AQP4 channels and DAPs in cerebellum. (A) Representative confocal imagestack projections (scale bars: $100 \mu \mathrm{m}$ ) show AQP4-IR in all layers of the cerebellar vermis in WT mice, with strong perivascular signal in the MCL (arrowheads) and along the GL (arrows), while in Dp71-null mice AQP4-IR was drastically reduced along capillary walls of the MCL. In Dp71-null mice, a low-intensity signal was still detectable in some capillaries (arrowhead) and GL (arrows), while AQP4-IR was mostly preserved in WM and GCL. (B) Semiquantitative analysis of AQP4 IR expressed as $\%$ of WT in MCL ( $\mathrm{n}=4$ WT and 5 Dp71-null mice). Residual IR in perivascular domains of the MCL in Dp71-null mice was estimated 30\% of WT levels $\left({ }^{*} p<0.05\right.$ ). (C-D) Analysis of AQP4 channels in cerebellar MCL by immunogold electron microscopy. Sample micrographs from a WT mouse illustrate AQP4 immunogold labeling (arrows) in macroglial membrane domains surrounding the vascular endothelium of a capillary (C, scale bar: $200 \mathrm{~nm}$ ) and along the GL (D, scale bar: $500 \mathrm{~nm}$ ). Histograms show AQP4 density as mean number of beads per $\mu \mathrm{m}(\mathrm{n}=2$ per genotype) along perivascular glial membranes (C; average of 18 capillary cross-sections per genotype; > $290 \mu \mathrm{m}$ of membrane) and along the GL (D; > $270 \mu \mathrm{m}$ of membrane per genotype). Sections without primary antibody were used as control (Ctrl). E: endothelium; L: capillary lumen; G: glial endfoot; asterisk: basal lamina. (E-F) Confocal image-stack projections show expression of the dystrophin-associated proteins (DAPs): $\beta$-dystroglycan ( $\beta$-DG; in E; scale bars: $80 \mu \mathrm{m})$ and $\alpha$-syntrophin $(\alpha$-SYN; in F; Scale bars: $100 \mu \mathrm{m})$. Histograms show quantification as $\%$ of WT ( $\mathrm{n}=4 \mathrm{WT}$ and 5 Dp71-null mice). IR for $\beta$-DG (E) and $\alpha$-SYN (F) were distributed along capillary walls and GL in WT mice. Expression of $\beta$-DG was reduced by about $50 \%$ in Dp71-null mice $\left({ }^{* *} p<0.01\right)$, whereas $\alpha$-SYN was completely absent in Dp71-null mice. MCL: molecular cell layer, GL: Glia limitans, GCL: granular cell layer, WM: white matter. 


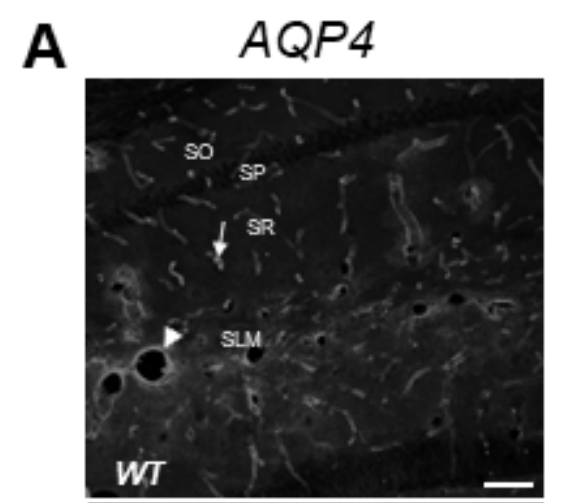

B
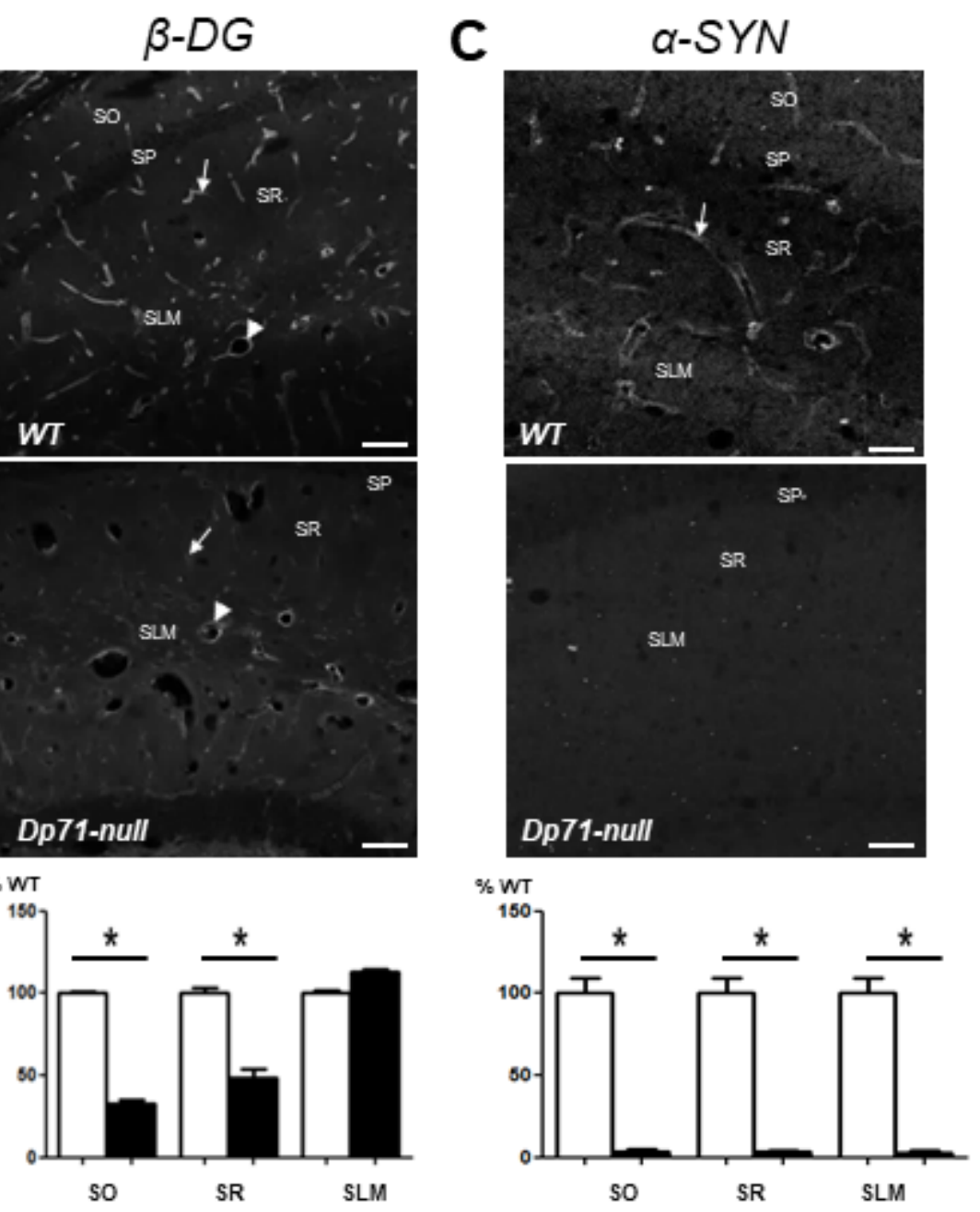

FIGURE 3. Immunolocalization of Dp71-associated proteins in hippocampus. (A-C) The IR for AQP4 (A), $\beta$-dystroglycan (B) and $\alpha$-syntrophin (C) was distributed in perivascular domains surrounding capillaries (arrows) and arterioles (arrowheads). Histograms show that expression of AQP4 and $\beta$-dystroglycan were significantly reduced in Dp71-null mice (black bars) compared to WT (white bars) in SO and SR layers, but not in the SLM, likely due to the residual expression seen in Dp71-null mice surrounding arterioles along the hippocampal fissure (arrowheads). The $\alpha$-Syntrophin-IR was completely absent in Dp71-null mice in all layers (C). SO: stratum oriens, SP: stratum pyramidale, SR: stratum radiatum, SLM: stratum lacunosum moleculare. All histograms show the mean \pm SEM of 4 WT and 5 Dp71-null mice; IR is expressed as \% of WT levels; ${ }^{*} \mathrm{p}<0.05$, significantly different from WT levels. Scale bars: $50 \mu \mathrm{m}$. 

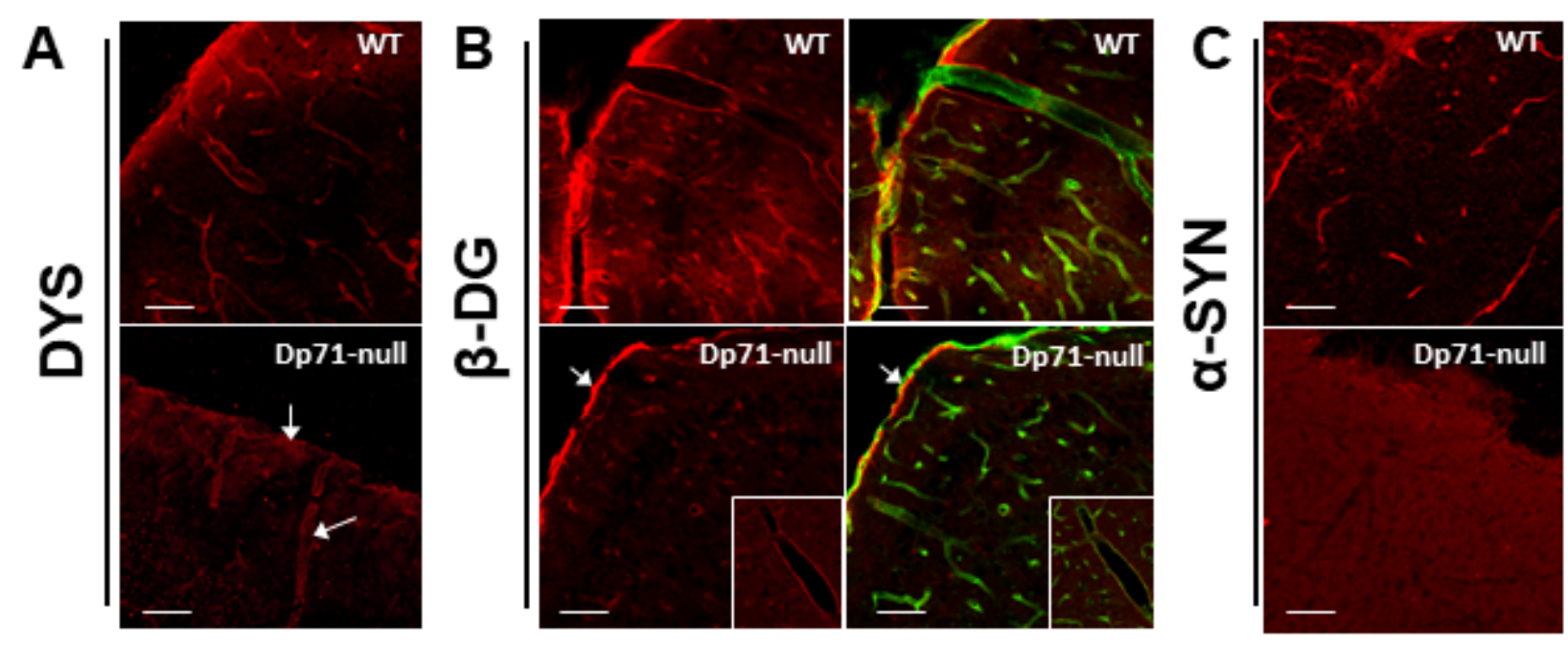

D
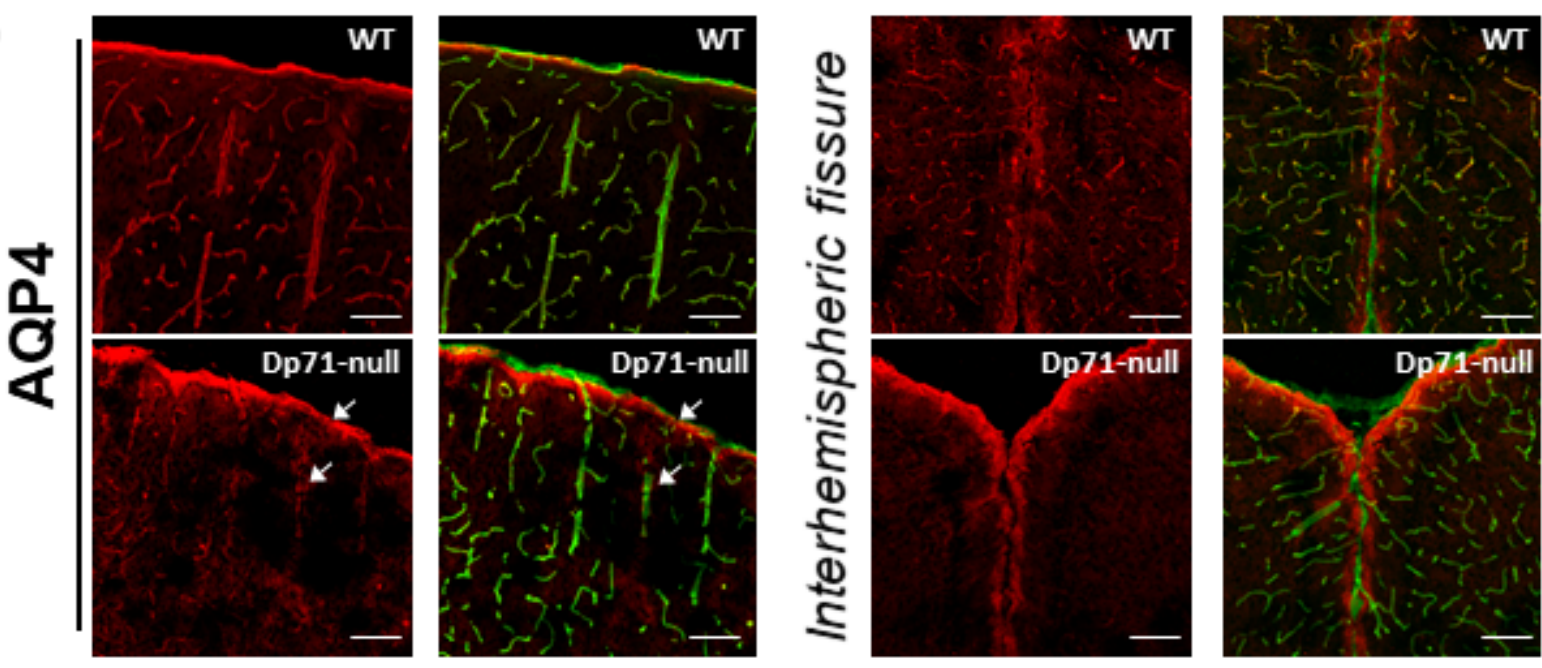

FIGURE 4. Immunolocalization of Dp71 and associated proteins in cortex. (A-D) The IR of dystrophins (A, DYS), $\beta$-dystroglycan (B, $\beta$-DG), $\alpha$-syntrophin (C, $\alpha$-SYN) and AQP4 (D) are shown in red; the endothelial marker (lectin) is green in overlays in B and D. All proteins were detected along the pial surface, penetrating arterioles and capillaries in WT mice. In Dp71-null mice, residual IR was detected for dystrophins (A), $\beta$-DG (B) and AQP4 (D, left panels), but not for $\alpha$-SYN (C), in the perivascular domains surrounding pial artery and penetrating arterioles (arrows; arteriole shown in inserts for $\beta$-DG). Faint residual IR around capillaries was seen in Dp71-null mice for DYS, $\beta$-DG and AQP4. Note that AQP4 IR was detected in both genotypes along the pial surface, including within the interhemispheric fissure (D, right panels). Scale bars: $50 \mu \mathrm{m}$ in A-C, 10 $\mu \mathrm{m}$ in $\mathrm{D}$. 

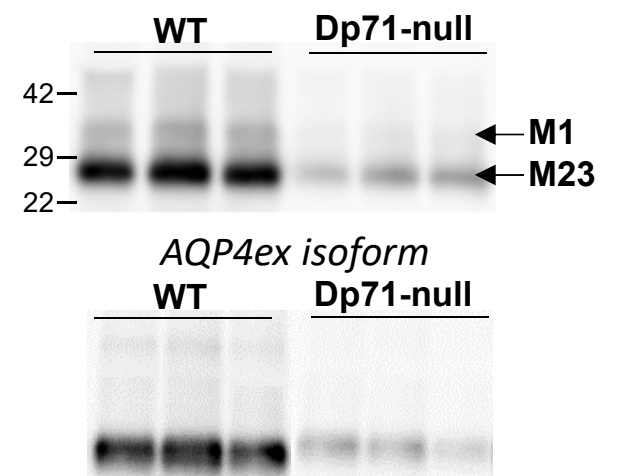
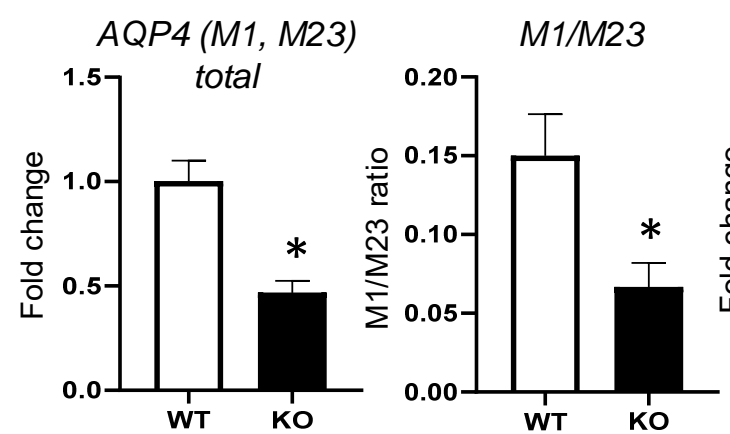
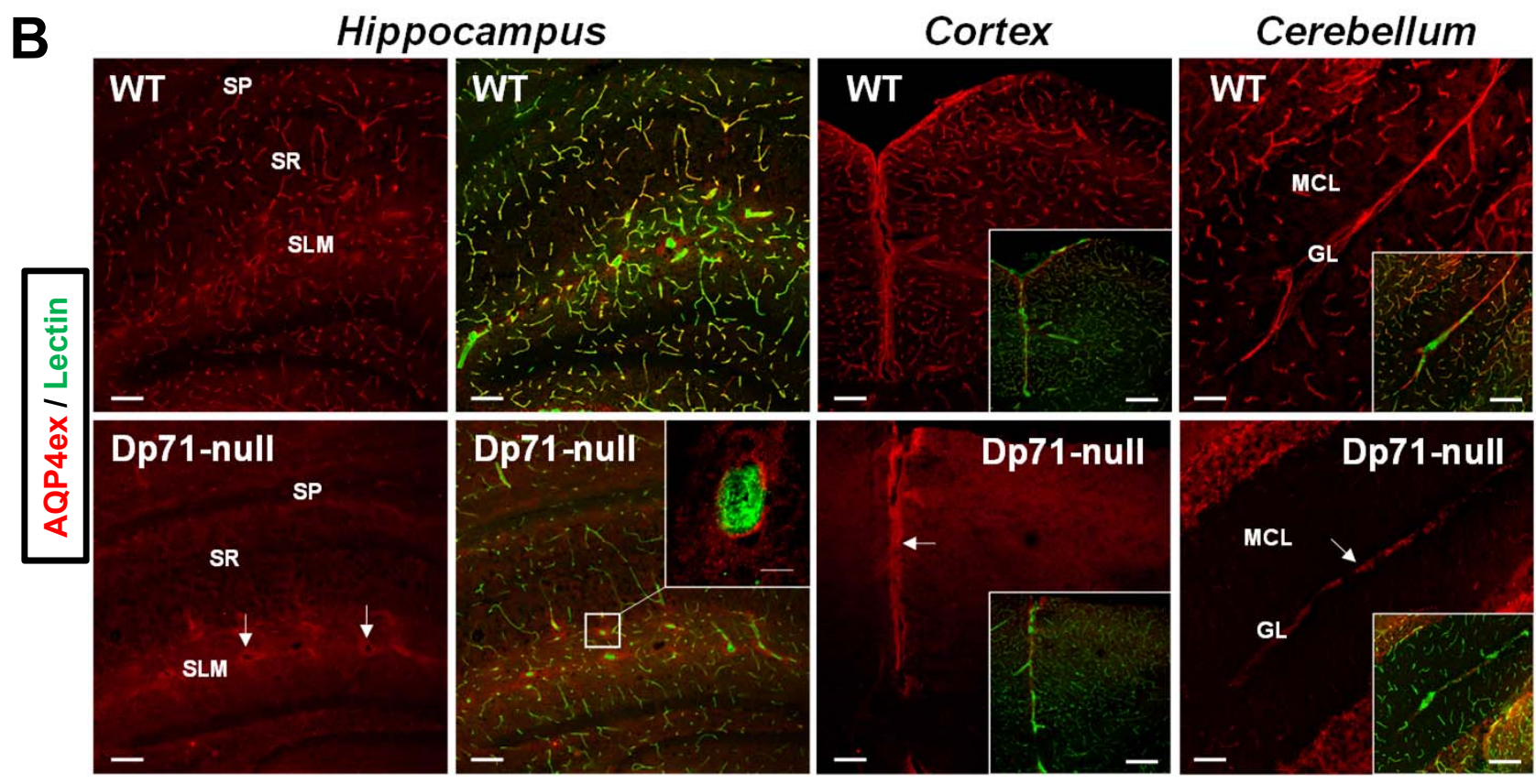

FIGURE 5. Expression of distinct AQP4 isoforms in the forebrain. (A) Western blots showing immunodetection of AQP4 isoforms (M1, M23 and AQP4ex, as indicated) in purified forebrain gliovascular units (vessels of 20-100 $\mu \mathrm{m}$ in diameter). Each lane is a pool of 3 distinct mouse samples; molecular weights indicated on the left. Histograms on the right show quantification of total M1 and M23 isoforms, M1/M23 ratio and AQP4ex (*p<0.05; significantly different from WT, $n=3$ pooled samples per genotype). (B) Immunolocalization of AQP4ex in hippocampus, cortex and cerebellum. AQP4ex IR (red) and endothelial marker (lectin, green in overlays) are shown in the three brain structures in WT and Dp71-null mice, as indicated. Note the loss of pericapillary IR in Dp71-null mice in all structures, while IR around large-caliber vessels was preserved (arrows). The insert in Dp71-null hippocampus shows that AQP4ex IR did not overlap with lectin around arterioles of the SLM (zoom of a transversal view of one arteriole). Hippocampal layers: stratum pyramidale (SP), stratum radiatum (SR) and stratum lacunosum moleculare (SLM); cerebellar layers: molecular cell layer (MCL) and glia limitans (GL). Scale bars: $100 \mu \mathrm{m}$ in main images; $25 \mu \mathrm{m}$ in the insert of Dp71-null hippocampus; $45 \mu \mathrm{m}$ in inserts of cortex and cerebellum. 

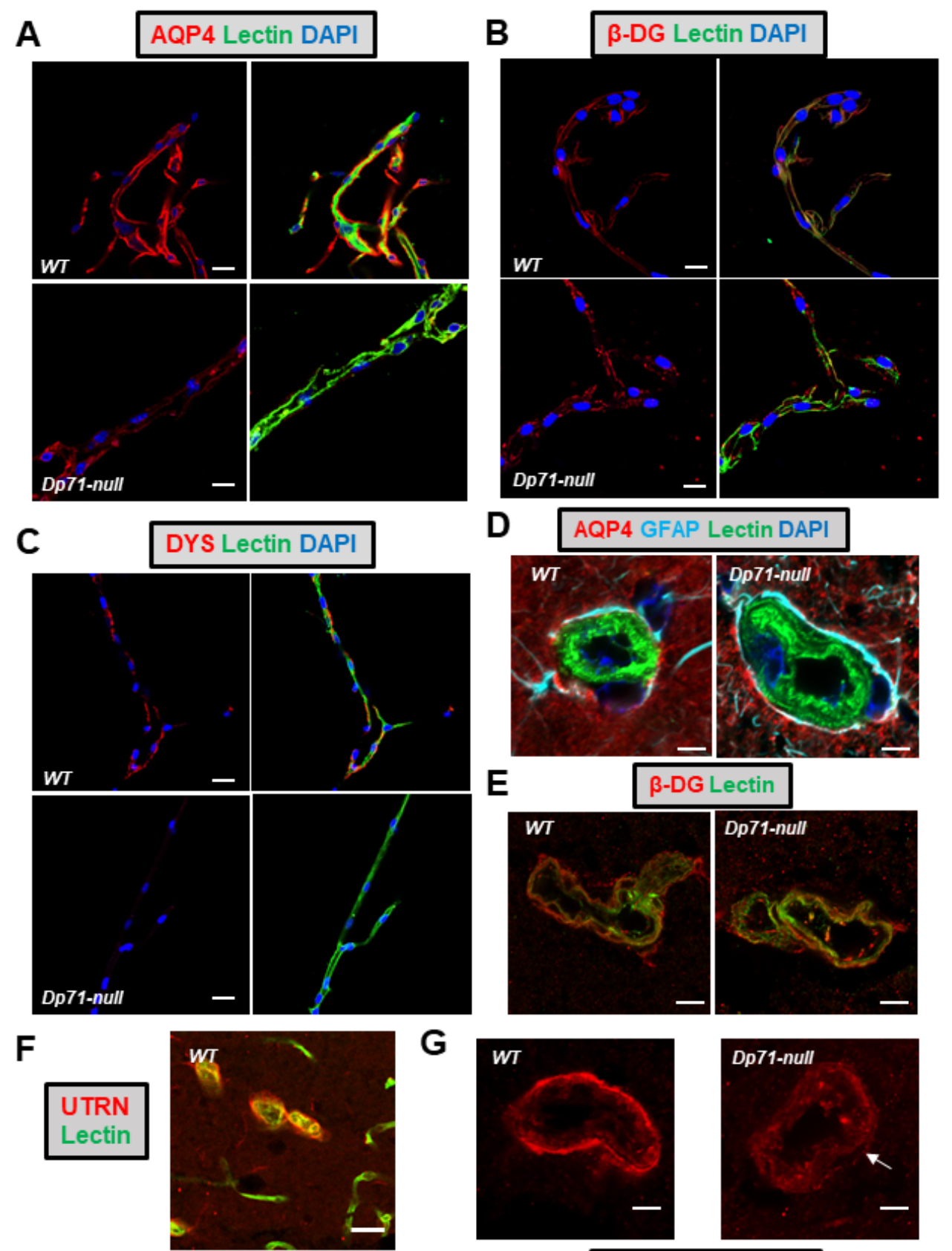

G
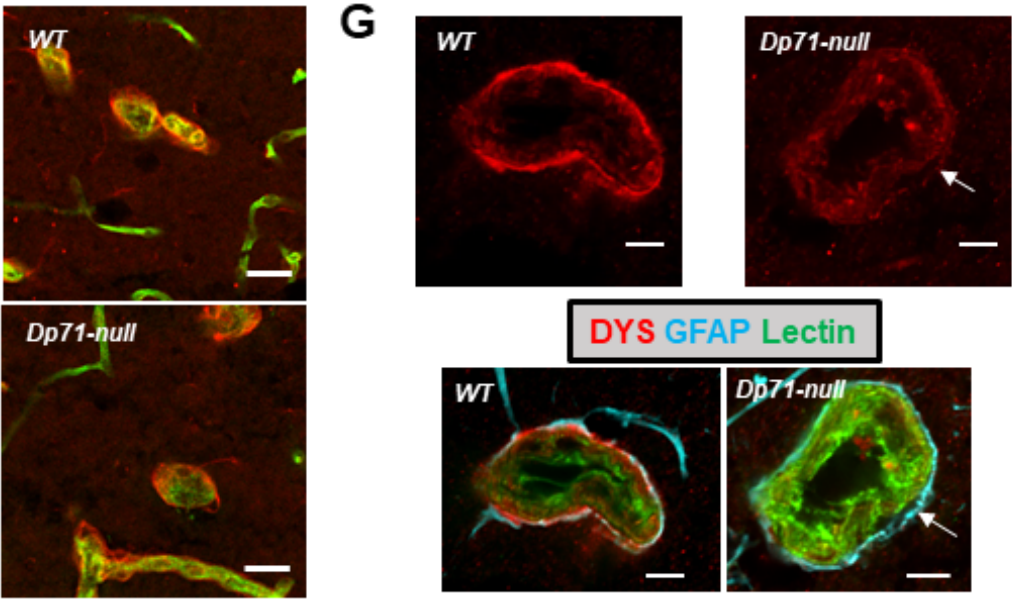

FIGURE 6. Subcellular localization of AQP4 and associated proteins in capillaries and arterioles. (A-C) IR for AQP4 (A), $\beta$-dystroglycan ( $\beta$-DG, B) and dystrophins (C) in purified gliovascular units from forebrain capillaries $(5-10 \mu \mathrm{m}$ in diameter) of WT and Dp71-null mice. The nuclear and endothelial markers, DAPI and Lectin, are shown in dark blue and green, respectively. (D-G) IR signals for AQP4 (D), $\beta$-DG (E), utrophins (F, UTRN) and dystrophins (G, DYS) in arterioles (diameter: $\geq 30 \mu \mathrm{m}$ ) of the hippocampal SLM region. Multiple staining for lectin (green), GFAP (cyan) and nuclei (DAPI, dark blue) are indicated as top panels. The arrows in G show dystrophin IR in GFAP-positive elements surrounding arterioles in Dp71-null mice. Scale bars: $15 \mu \mathrm{m}$ in $\mathrm{A}-\mathrm{C}, 10 \mu \mathrm{m}$ in $\mathrm{D}, \mathrm{E}, \mathrm{G}$, and $25 \mu \mathrm{m}$ in $\mathrm{F}$. 

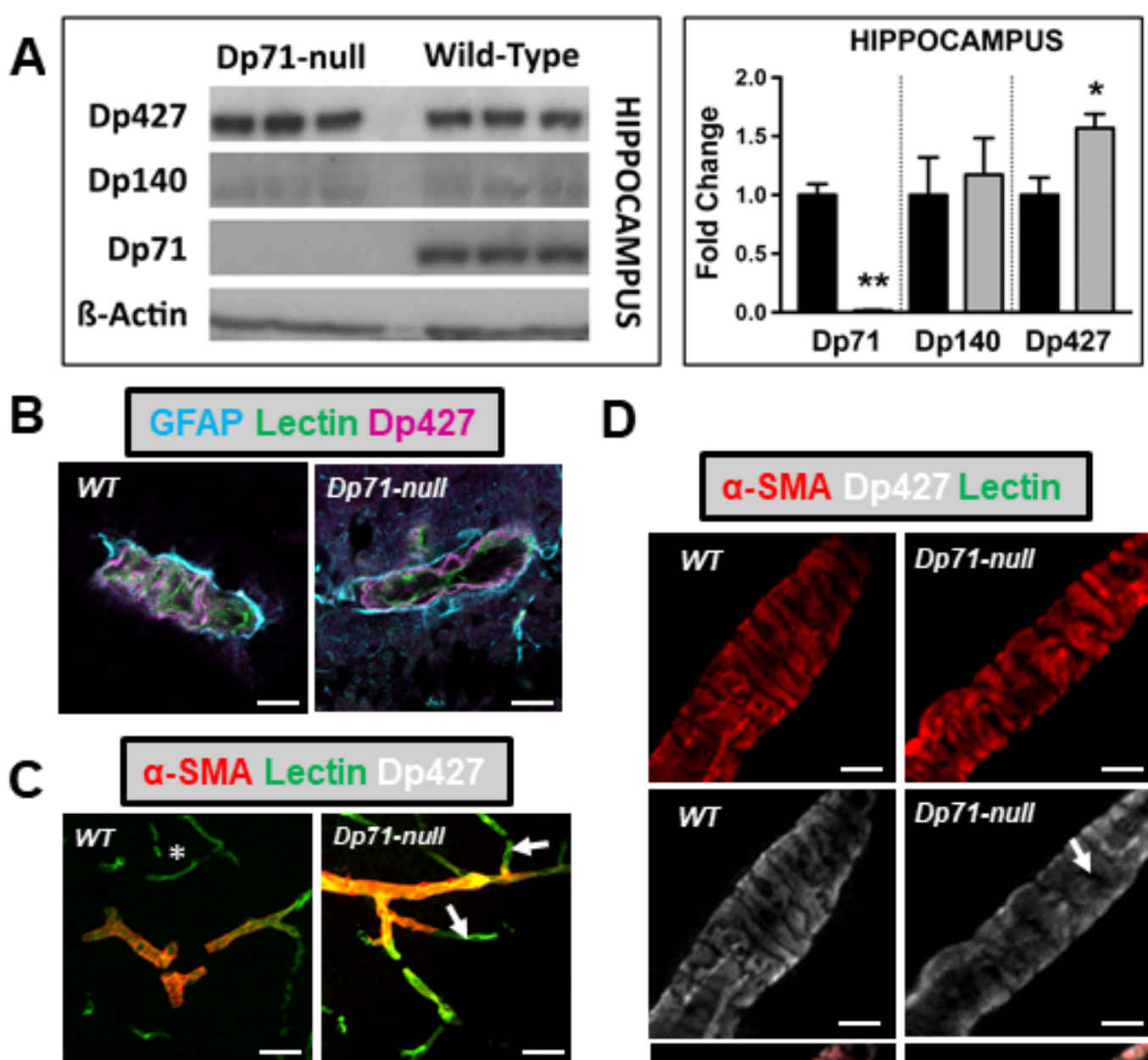

D
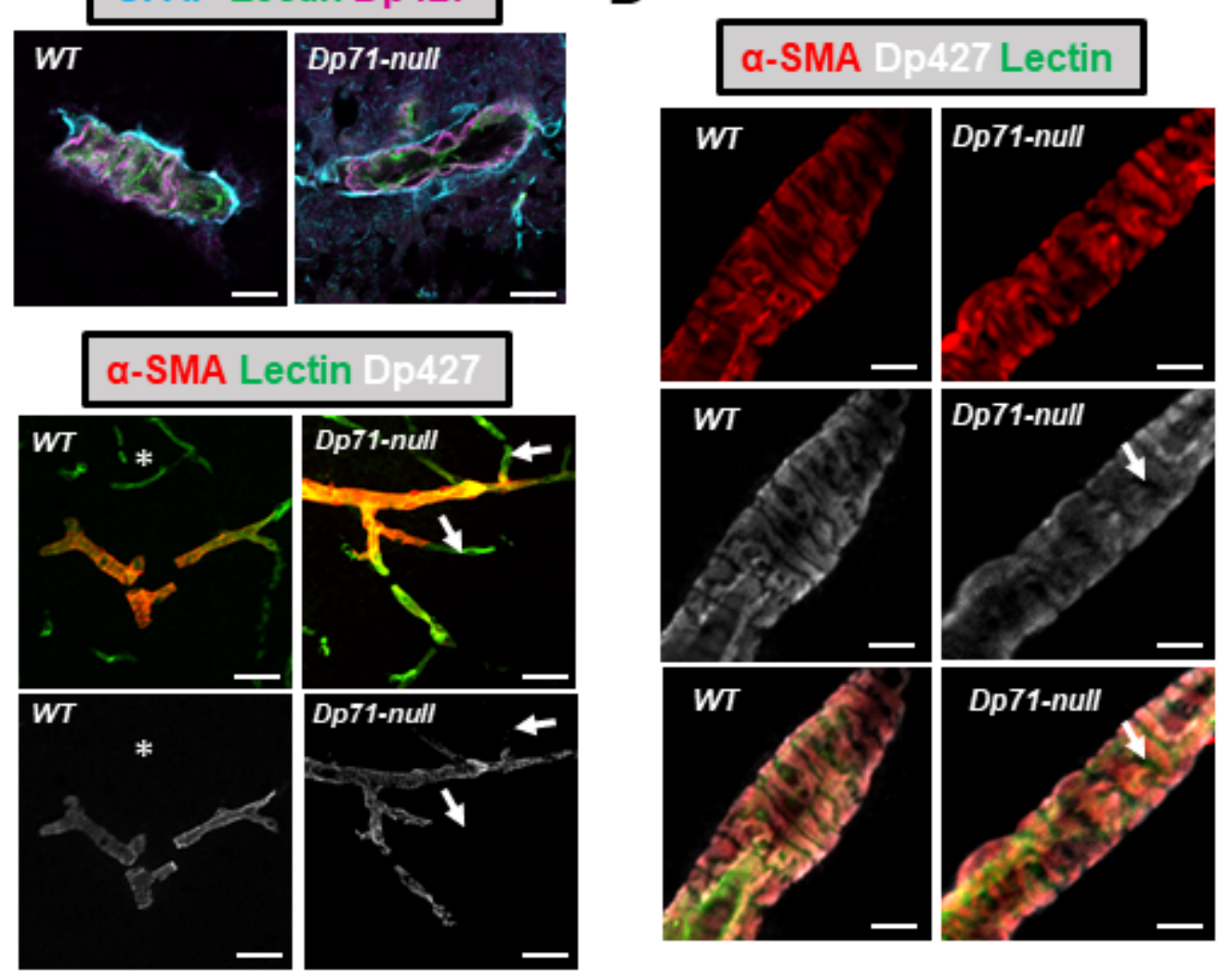

FIGURE 7. Immunolocalization of Dp427 dystrophin in the vascular compartment. (A) Western blots showing expression of dystrophins (Dp427, Dp140, Dp71) and $\beta$-actin (loading control) in WT and Dp71null mice ( $\mathrm{n}=6$ per genotype). The histogram shows data expressed as the mean fold change $( \pm$ SEM) compared to WT. Dp427 expression was significantly higher in Dp71-null mice compared to WT. ${ }^{*} \mathrm{p}<0.05$; $* * p<0.01$; significantly different from WT. (B) Detection of Dp427 (magenta), GFAP (cyan) and lectin staining (green) in arterioles (diameter: $\geq 30 \mu \mathrm{m}$ ) of the hippocampal stratum lacunosum moleculare (SLM). (C) The upper panels show double labeling of arterioles, precapillary arterioles and capillaries (asterisk in upper left image) with smooth-muscle marker $\alpha$-SMA (red) and lectin (green) in a hippocampal tissue section. Note that overlapping IR (yellow-orange) is only present in large diameter vascular elements (i.e., arterioles and initial segment of precapillary arterioles). The lower panels show Dp427 IR in the same vessels; IR was restricted to the large-diameter precapillary arterioles (white), not in smaller precapillary arterioles (arrows) or capillaries (asterisk). (D) Detection of the smooth-muscle marker $\alpha$-SMA (red), Dp427 (white) and lectin (green) in purified arterioles. Note that Dp427 and $\alpha$-SMA IR is localized in the same vascular subdomains but does not overlap with the IR of endothelial marker lectin (arrow). Scale bars: 10 $\mu \mathrm{m}$ in $\mathrm{B}, 15 \mu \mathrm{m}$ in $\mathrm{C}, 20 \mu \mathrm{m}$ in $\mathrm{D}$. 

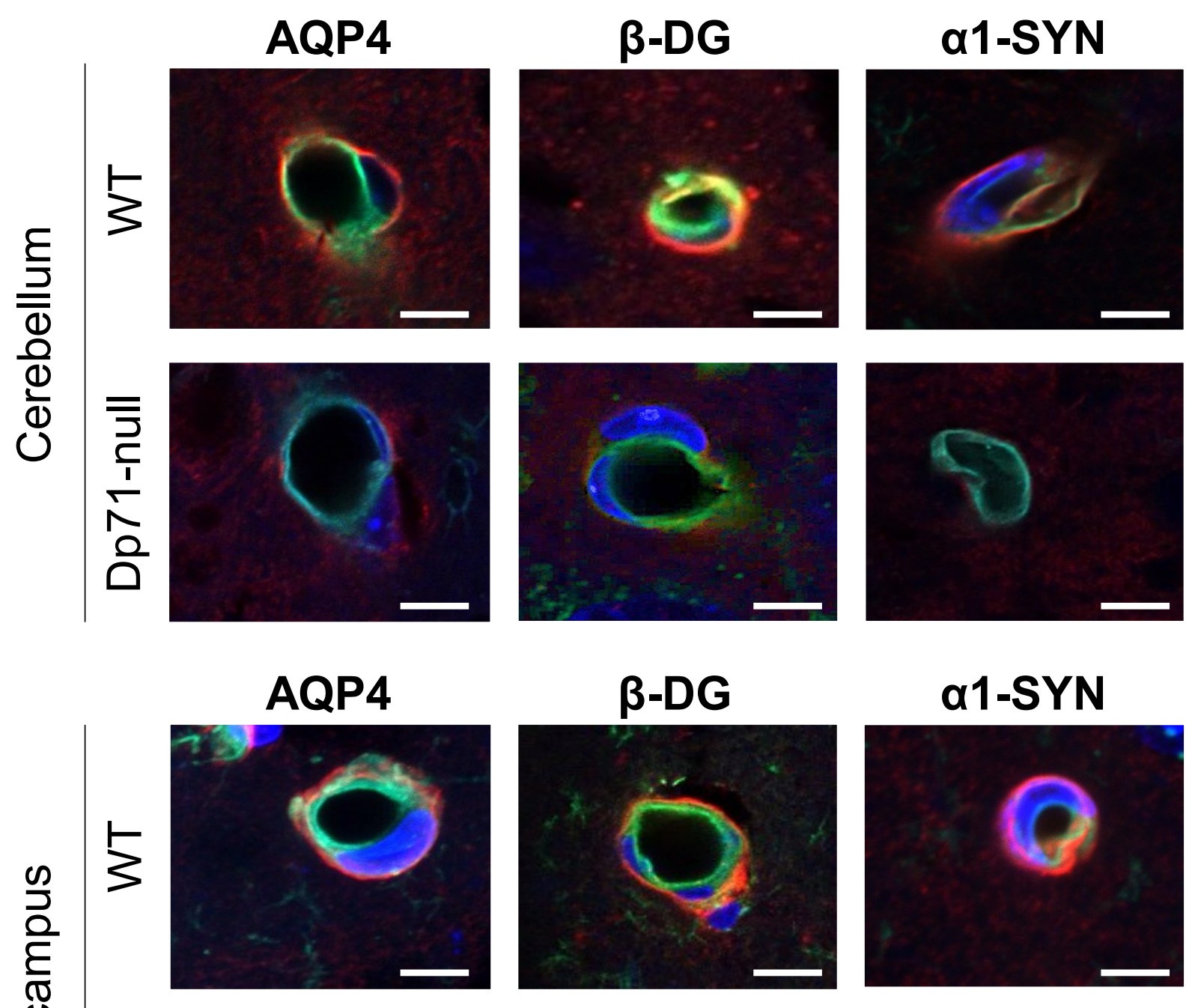

\section{$\beta$-DG}
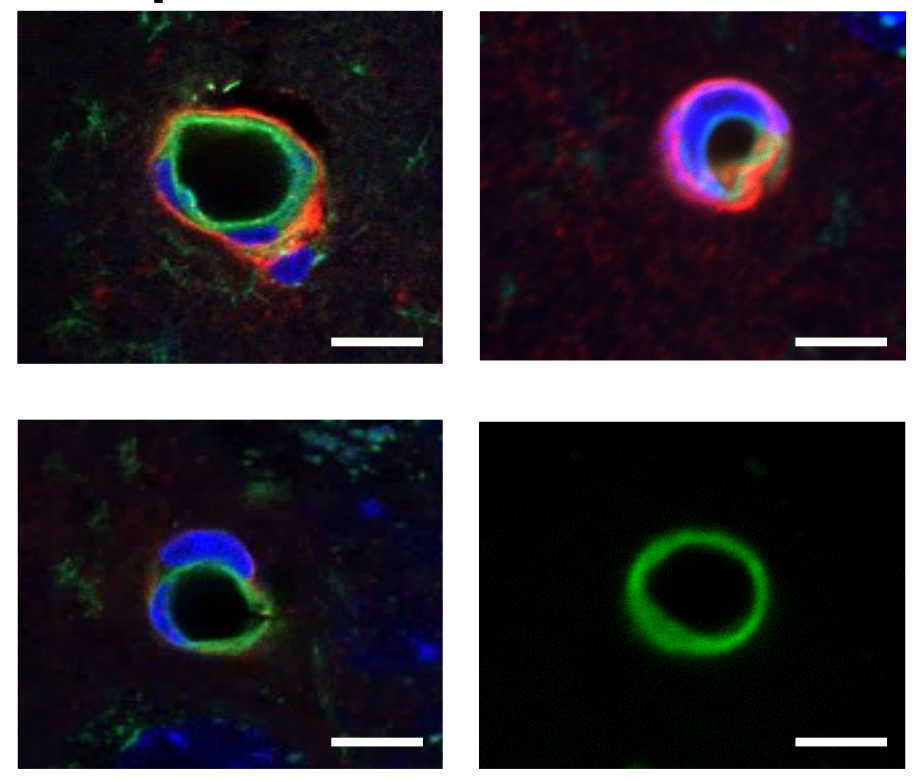

AQP4 / $\beta$-DG / a1-SYN Lectin DAPI

Supplementary Fig. S1. Subcellular localization of Dp71-associated proteins in brain capillaries. Transversal planes showing double labelling of capillaries from cerebellum and hippocampus, as indicated on the left. IR obtained with primary antibodies directed against AQP4, $\beta$-dystroglycan ( $\beta$-DG) and $\alpha 1$-syntrophin $(\alpha 1-\mathrm{SYN})$ are shown in red. Vascular endothelial cells were labeled with lectin (green) and DAPI (blue) was used as nuclear stain. Scale bar: $5 \mu \mathrm{m}$. 

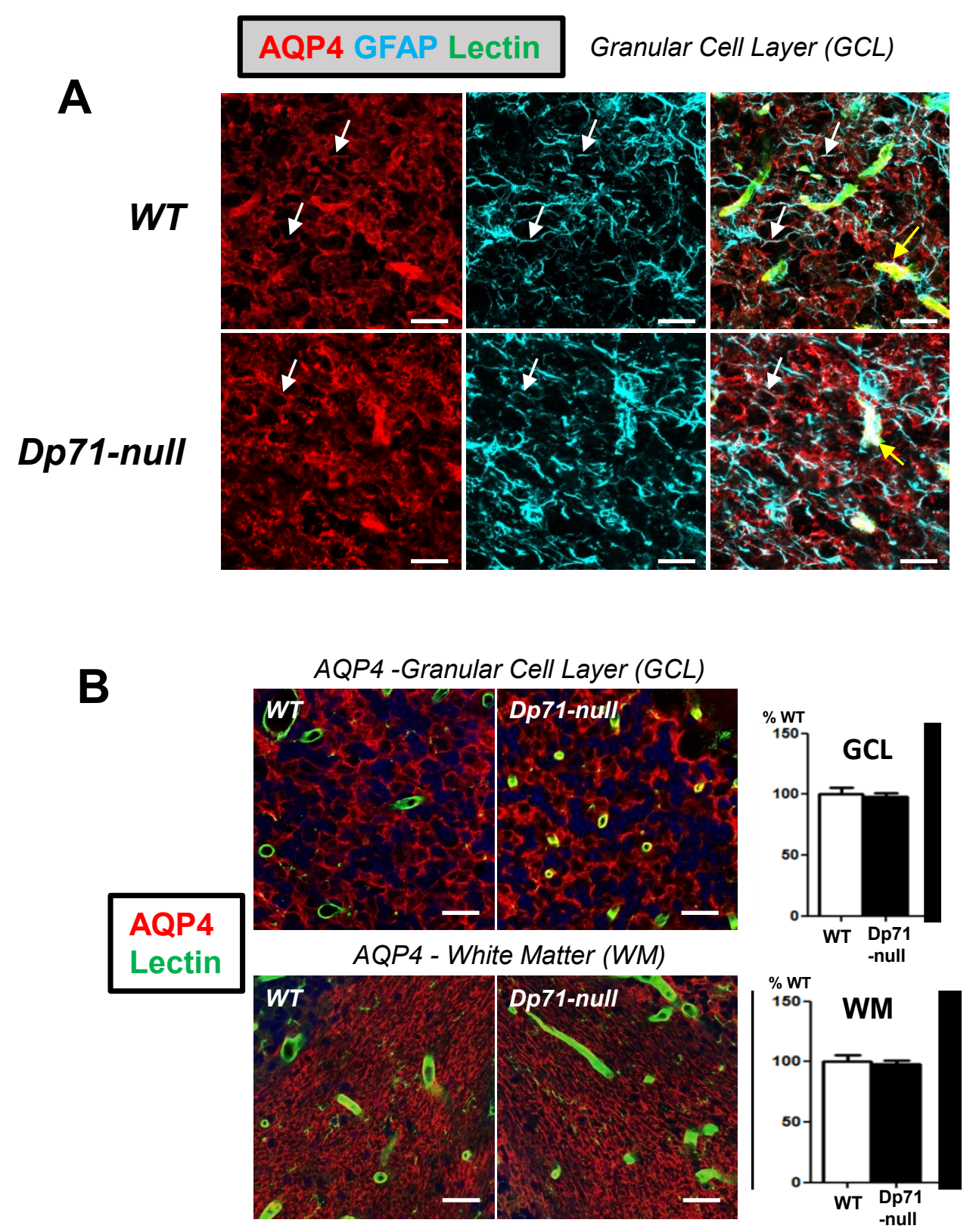

Supplementary Fig. S2. Immunolocalization of AQP4 channels in granule cell layer and white matter of cerebellum. (A) Representative image-stack projections obtained by confocal laser scanning microscopy following triple fluorescent staining of AQP4 (red, left panels), GFAP (cyan, middle panels) and lectin (green, merged in right panels) in granular cell layer. Partial colocalization of AQP4-IR with GFAP-IR is shown by white arrows in left and middle panels. The merged IR signals reveals colocalization of the 3 markers in perivascular regions in both genotypes (yellow arrow in right panels). Scale bars: $20 \mu \mathrm{m}$. (B) AQP4-IR in the granular cell layer (GCL) and white matter (WM). Most of the IR showed no overlap with lectin (green), suggesting a main expression in astroglial processes in the GCL and in fibers of the WM. Histograms show a semiquantitative analysis of AQP4 IR in cerebellar GCL and WM (Mean \pm SEM of 4 WT and 5 Dp71-null mice; expressed as \% of WT levels). Quantification did not reveal any genotype difference in these layers. Scale bars: $20 \mu \mathrm{m}$. 